\title{
Percent Black: Regionalism, URbanism and Group Threat as EXPLANATIONS FOR RACIAL DISPARITIES IN IMPRISONMENT 1985-2001
}

Pamela E. Oliver

Note: Working paper last updated July 2011.

\section{Abstract}

Black prison admission rates \& Black/White disparities in prison admissions 1985-2001 were lower in the Old South than in the North. Detailed examination shows a threshold effect: the minimum Black imprisonment rate was uncorrelated with percent Black, but very high Black imprisonment rates occurred only where the percent Black was relatively low. This is not explained by the statistical instability of small populations: although there is more instability where the percent Black is low, the pattern holds up for places with large Black populations. It is also not explained by urbanity as the pattern replicates for metropolitan areas. In addition, the assumption that imprisonment is basically an urban phenomenon is wrong: Whites have higher imprisonment rates in rural areas, and the urban-rural difference for Blacks declined to a low level by the end of the study period. Other minorities are briefly discussed, showing that each has a distinctive pattern. Overall the data refute simplistic theories of group threat and support social control theories that consider both the capacity and desire for social control.

Many in the North find it surprising that the Black/White disparity in imprisonment is especially high in the upper Midwest (Minnesota, Wisconsin, lowa) and the Northeast (Pennsylvania, New Jersey, Connecticut), while the states of the Old South stand out (along with Hawaii, Vermont and Idaho) as having a particularly low racial disparity (see Figure 1). This is not consistent with Northern stereotypes about race relations. Until recently, scholars have not attended to this pattern because they focused on the total imprisonment of all races combined. As Figure 1 shows, the total incarceration rate is relatively high in the South, although it is also high elsewhere. More specifically, the total imprisonment rate is higher where Blacks are a higher percentage of the population as can be seen, for example, in Figure 2, which shows the relation for the late 1990s. This pattern has long been documented and has often been seen as support for variations of threat theory or "Black criminality" explanations of incarceration patterns (Arvanites 1997; Arvanites and Asher 1998; Greenberg and West 2001; Jacobs and Carmichael 2001). The trouble is, these studies contain an aggregation error. Because the Black-White disparities in arrest and imprisonment are so high, percent Black is nearly always a significant predictor of total imprisonment rates: it is mostly Blacks who are being imprisoned.

The race-specific incarceration rates tell quite a different story. Although people unfamiliar with the issues, including many social scientists, are surprised by the fact that Black incarceration rates and the Black/White 
disparity tend to be lower in the South than in the North, and lower where Blacks are a larger share of the population, this pattern has showed up in study after study over many years and is quite robust. For example, the pattern appears in the tables in Christianson (1981) but is never mentioned in the text, while Hawkins and Hardy (1989) report the pattern for the Black/White imprisonment disparity but do not discuss it. Crawford, Chiricos, Kleck (1998) study racial disparity in sentencing in Florida where their main emphasis is on documenting that the disparity cannot be explained away by other factors; they report that racial difference in sentencing more apparent in lower percent Black contexts. Scholars puzzled by the pattern have advanced a variety of possible explanations that treat it as an artifact. For example, Blumstein $(1982 ; 1993)$ considered three possibilities for the pattern: (1) Blacks in South are more compliant; (2) Blacks in the North live in more high crime areas; (3) A compositional effect, wherein liberal states send only serious offenders to prison and the racial differential in arrest (or offending) is highest for very serious crimes, so transparent processing would lead to high imprisonment disparities. Langan (1991) notes the pattern and attributes much of the growing national disparity in imprisonment between 1926 and the 1970s to the migration of Blacks from the South to the North and West, where Black incarceration rates were higher (a speculation that, it turns out, is not correct). ${ }^{1}$ DeLisi and Regoli (1999) even go so far as to adduce this pattern as "proof" that racial disparities in imprisonment cannot be due to prejudice, since (they assert) it is not feasible that the South is less prejudiced than the North!

There is also more recent work that acknowledges the political/racial dimensions of social control without taking account of racial dynamics. Despite citing earlier findings about the percent Black effect, Yates (1997) does not include relative population size in his analysis of the average 1991-3 disparity in imprisonment rates for 49 states, but takes a political approach, linking the Black/White disparity negatively to historical levels of Black insurgency and the presence of Black elected officials and positively to Black/White inequality and the Black/White disparity in statewide urban concentration. Keen and Jacobs $(2009)^{2}$ find this pattern puzzling and argue for a combined voting threat and power theory to produce a curvilinear relationship in predicting the Black/White incarceration ratio. 


\section{EXPLAINING THE PATTERN AS A BALANCE OF POLITICAL FORCES: BLALOCK REVISITED}

The first serious engagement with the racial pattern of imprisonment is the landmark study of the 1982 prison census by Bridges and Crutchfield (1988). They model the disparity as the difference in the logs of the White and Black imprisonment rates and distinguish the factors predicting the White rate from those predicting the Black rate. Controlling for arrest rates, legal factors, and measures of inequality, they find that the percent Black along with Black urbanization are associated with lower Black imprisonment, higher White imprisonment, and lower racial disparity in imprisonment. Anticipating a political model of ethnic conflict and social control, they say clearly that this is likely due to a threshold "at which the economic costs to white taxpayers of controlling the minority population through imprisonment exceed the benefits of racial discrimination in this form of control" (p. 717). In their conclusion, they highlight the lower disparity in the South and stress that explanations "centered solely on class-based racism against blacks are inadequate" and that adequate theories cannot just be grounded in normative theories of punishment by an entire society but must include recognition that "punishment is a mechanism used by dominant groups in society to subjugate minorities independent of their involvement in criminal acts."

Many scholars (except Bridges and Crutchfield) who have found the negative relation between percent Black and the Black imprisonment rate have tended to discount it as either a statistical artifact or a result of some additional extraneous variable such as urbanization. We will consider these possibilities below. But as Bridges and Crutchfield noted, this pattern really is not at all surprising theoretically. Social control is two sided. It is not enough to want to control a threatening group; the authorities also need to have the capacity to exercise control. Incarceration is a particularly expensive form of social control. There has to be an upper limit on the proportion of a population a regime can afford to withdraw from the productive labor force and house and feed at state expense. In addition, even minorities have votes in a democratic society and a voting minority exerts increasing influence on social policies as its size increases. That is, the sheer size of a minority group is related to some forces ("threats") that tend to increase the authorities' use of incarceration and other forces ("constraints") that tend to decrease the authorities' use of incarceration. Thus the actual incarceration rate is a complex composite of these forces. 
This explanation is anticipated in Blalock's classic Toward a Theory of Minority Group Relations (1967). His arguments are typically reduced to a gratuitous citation or trope that social control goes up with threat ${ }^{3}$ or the almost-as-simplistic trope that there is a curvilinear relation between minority group size and the level of threat. But his actual arguments recognize the complex interplay between different aspects of inter-group dynamics and power relations. The main thrust of its argument is that relative group size alone never explains inter-group conflict. He analyzes conflict as a two-actor problem and stresses the importance not only of each group's size and but also its level of mobilization, arguing that the outcome is a multiplicative function of resources and mobilization. He explicitly recognizes the importance of group organization and collective action, and of possible constraints on that action. His prediction of a curvilinear relation between a minority group's relative size and the discrimination or repression it experiences is understood as the net result of multiple processes: the dominant group's desire and ability to discriminate, and the subordinate group's ability to resist discrimination. This recognition that the outcome of any dominant/subordinate or majority/minority conflict is a product of multiple contingencies is typically missing from work that cites him.

\section{CLARIFYING THE PATTERN: NECESSARY BUT NOT SUFFICIENT}

Before we get too deeply involved in interpreting this relationship, it is helpful to specify it. One question is whether there is anything to explain. Is this just some kind of statistical artifact? It is worth spending some time on this question here because this will allow us to get a good feel for the data patterns that will give us a better ability to appreciate more complex analyses. Figure 3 shows the scatter plot of the average Black imprisonment rate $1993-1998$ by the state's Black population proportion; the circle size around the state initial is weighted by the size of the Black population. Only Southern states are more than $18 \%$ Black, but both Southern and Northern states are between 8 and $18 \%$ Black. ${ }^{4}$ The graph seems to show a kind of discontinuity or threshold effect somewhere around $12 \%$. Above the threshold, there does not seem to be a relation, and all the states except Delaware have moderately low Black imprisonment rates. Excepting Delaware, very high Black imprisonment rates occur only in states below this threshold. The average Black imprisonment rate tends to be highest when Blacks are about $5-10 \%$ of the population. Below $5 \%$ the dispersion increases markedly as many of the states with low percent Black are small states with very few Black residents. Massachusetts seems to stand out as having a low 
Black imprisonment rate despite having a low percent Black and a significant Black population. Otherwise, among the larger Black population states, the negative relation between Black population percentage and the Black imprisonment rate seems clear.

Figure 4 plots the Black/White disparity ratio in imprisonment against the percent Black. Again the circle sizes represent the Black population size. In this graph, many states regardless of percent Black have Black/White disparity ratios between 5 and 10, but the only states that have disparity ratios higher than 10 are less than $15 \%$ Black. The states that are less than 5\% Black typically also have very small Black populations and a very wide dispersion in Black imprisonment rates. But it is clear that statistical instability due to small populations does not explain the main pattern, as there are very large Black populations in populous states that have lower Black population percentages.

The Black/White disparity ratio is a function of both the White and Black imprisonment rates. Surprisingly, the disparity ratio is only moderately correlated with the Black incarceration rate. Figure 5 shows that there is wide variation in the disparity ratios for states with moderate or high Black imprisonment rates and a wide variation in Black imprisonment rates for states with similar disparity ratios. In fact, the correlation is much stronger for the relation between the White incarceration rate and the Black/White disparity, as can be seen in Figure 6 . That is, the disparity ratio is often especially high where the White incarceration rate is especially low. We also see a similar dispersion issue: the Black/White disparity is more variable where the White incarceration rate is low, while the disparity is more consistently low where the White incarceration rate is high. This points to an important issue in understanding the racial politics of social control: we have to pay attention to what is happening with Whites just as much as with what is happening with Blacks.

So how are Whites treated in those Southern states with high percent Black? As Figure 7 indicates, the White incarceration rate is not especially correlated with the percent Black, except that the states with a high proportion of Black residents tend to have consistently middling White incarceration rates, while the White incarceration rates are much more variable for the low percent-Black states. Some of the highest White incarceration rate states are Alaska, Nevada, Oklahoma, Arizona, Texas, Hawaii, and California-states that are relatively low in their percent Black but have some other large minorities (or in the case of Hawaii, an Asian 
majority). We can get a sense of the relation between the White imprisonment rate and the proportion of the population that are non-Hispanic Whites (versus all minorities) in Figure 8. There is still no strong relationship, except that the highest White imprisonment rates are found in states that are $80 \%$ or less White, but there are also very low White imprisonment rates in this range, especially between $60-80 \%$ White.

Although some states change, the basic pattern seen for 1993-1998 in Black imprisonment and the Black/White disparity ratio has existed since the 1920s (Oliver 2008): states with higher Black population proportions have relatively low Black imprisonment rates and disparity ratios, while the rates and disparity ratios are much more dispersed and on the average higher for states with smaller Black population proportions.

To sum up, the states of the Old South are fairly consistent in having relatively low Black imprisonment rates and middling White imprisonment rates, leading them to have some of the lowest Black/White disparities in imprisonment. Beyond these states, there is tremendous variability in both Black and White imprisonment rates. The most plausible explanation for this pattern is that having a relatively low Black population proportion (somewhere under $20 \%$ ) is a necessary but not sufficient condition for having a very high Black imprisonment rate. It is just not possible to incarcerate too large a share of a total population. In turn, this pattern is quite consistent with the theoretical idea that there are cost constraints or other constraints on the extreme to which a dominant group can exercise whatever taste or motivation it has for exerting domination through imprisonment of a minority group.

\section{THE MATTER OF URBANITY}

It is generally assumed that crime and incarceration are bigger problems in big cities, and one speculation is that the reason incarceration rates in the South are lower where the percent Black is higher is just the fact that Black people in the North are nearly all living in cities. Only in the South do a significant minority of Black people live in rural areas. A state's percent Black is very highly correlated with the level of Black urbanization, so that empirically it is very difficult to distinguish them in state-level data. Running counter to the idea that urbanization is somehow the "real" factor is that the level of White urbanization in a state is only very weakly correlated with the level of White imprisonment, as Figure 9 indicates. It turns out that urbanity does not explain away the negative relation between the percent Black and Black imprisonment. Instead, digging into the matter of urbanity 
reveals previously-unrecognized information about what has been happening with Whites.

To study urbanity we have to shift from the CPUS for all 50 states to National Corrections Reporting Program (NCRP) data where we have complete information for only 25 states. ${ }^{5}$ We are able to group prison admissions by county of sentencing and to group them into metropolitan areas. All the counties within a state that are not part of a metropolitan area are grouped together as the state's rural balance. ${ }^{6}$ The NCRP subsample is for 1985-2002, and we get some snapshot views by dividing it roughly into two pieces at 1995 , since the national trends show that the racial disparity began falling in 1995.

First we examine Black imprisonment rates to address the question of whether the previous percent Black finding is an artifact of urbanity. The answer is no, it is not an artifact. Black prison admission rates for 1985-1994 are shown in Figure 10 and for 1995-2002 in Figure 11. The basic pattern replicates for prison admissions in metro and non-metro areas: all the really high Black prison admission rates occur below about $18 \%$ Black, and there is a negative correlation between proportion Black and the Black prison admission rate for both metropolitan and nonmetropolitan areas. The signed $\mathrm{R}^{2}$ is lower than for states, capturing the greater variability among local places. The average trend lines for metropolitan and nonmetropolitan areas are also plotted in the graphs. They reveal that the metro-nonmetro gap in 1985-1994 decreased to zero as the proportion Black increased. Prison admissions are heavily influenced by revocations, so we also examine new prison sentences (which will prove important for understanding White trends) in Figure 12 for 1985-1994 and Figure 13 for 1995-2002. These figures show a metrononmetro gap in 1985-1994 that declines with proportion Black but does not go to zero, while for 1995-2002 the gap virtually disappears.

The lack of a metro-nonmetro gap for Blacks for 1995-2002 is contrary to all the usual assumptions that crime and imprisonment are fundamentally urban phenomena. The challenge to this assumption is even greater with the White data. Figure 14 for 1985-1994 and Figure 15 for 1995-2002 show that metro and nonmetro areas have largely overlapping distributions for White prison admissions. The metro-nonmetro gap is very small for the majority of areas that are less than $10 \%$ Black, and the nonmetro areas that are at least $10 \%$ Black actually have higher average White imprisonment than the comparable metro areas. The relation to the proportion Black is essentially zero, as it is for the states, although it tended positive for nonmetro areas in 1985-1994. Metro- 
nonmetro comparisons for White total admission rates are distorted because California alone accounts for $34 \%$ of all White revocation admissions in the data; next in line behind it are Missouri with $7 \%$ and Texas with $6 \%{ }^{7}$ If we focus on new sentences in Figure 16 for 1985-1994 and Figure 17 for 1995-2002, we see that by the later period the White nonmetro new prison sentence rates are consistently higher than the metro rates; in the earlier period this is also true for areas that have non-trivial Black populations. Where the proportion Black is less than $5 \%$, metro and nonmetro areas had the same average in the earlier 1985-1994 period.

Finally, if we look at the disparity ratio, which is a composite of the Black and White trends, we see that the Black/White disparity is consistently lower in nonmetropolitan areas for prison admissions in both 1985-1994 (Figure 18) and 1995-2002 (Figure 19) and for new sentences in 1985-1994 (Figure 20) and 1995-2002 (Figure 21). The size of the metro-nonmetro gap in the disparity is smaller where the percent Black is higher.

We will dig much more into these trends below. For now we note two things. First, the assumption that imprisonment trends are all about urban areas is wrong: the rural/urban gap for Blacks was not large and declined over time, and the rural/urban gap for Whites goes the other way-Whites have higher imprisonment rates in rural areas. There is a lot going on in the rural areas with Whites that has been ignored. Second, these graphs point to a phenomenon we will explore further below: the time trends for Whites and Blacks differed markedly by type of place. It turns out that the national trends are a composite of one set of trends that were happening in the large metro areas with large Black populations and a very different set of trends that were happening in the nonmetro areas and smaller cities with small Black populations. A much higher fraction of the White population than the Black population lives in the nonmetro areas of the US. A short version of the punchline is that the Black trends were driven primarily by what was happening in the large metropolises while the White trends were driven more by what was happening in the rural areas and small cities. ${ }^{8}$

\section{Regionalism and Percent Black: Conclusions}

We began with the surprise that the states of the Old South - Louisiana, Mississippi, Alabama, Georgia, South Carolina, North Carolina and Virginia - have low Black imprisonment rates and a low Black/White disparity ratio. We showed that the key factor is not southern latitude or prior status as a slave state, but the proportion of the state's population that is Black. We showed that the highest Black incarceration rates occur in states with low 
Black population proportions. Black incarceration rates are much more variable for states that are less than $20 \%$ Black, especially for the states with very small Black populations. This is not just sampling instability on small populations. The largest Black populations are actually in New York, California, and Texas - states with smaller Black population proportions - and these states have much higher Black incarceration rates than the Southern states. Although there is a strong negative relation between a state's percent Black and its rate of Black urbanization, this does not seem to explain away the relationship. MSAs that are more than $25 \%$ Black have much lower rates of Black prison admissions than those with lower Black percentages. MSAs that are less than $20 \%$ Black are much more variable in their prison admission rates and include some of the especially high Black imprisonment rates as well as low rates. Patterns for other ethnic groups at the state level are similar in being much more variable where the minority population proportion is under $10 \%$ but, at the state level, do not exhibit a negative relation between population representation and the incarceration rate. However, at the MSA level, the pattern for Hispanic prison admissions is similar to the pattern for Blacks. This pattern also replicates for Black arrests and the Black/White disparity in the prison/arrest ratio. It was also found in the extraordinary rise in Black drug sentences in the late 1980s and early 1990s in the peak of the drug war.

When we look at the scatter plots, we see a pattern that is obscured when we just calculate means or run regression equations: the minimum imprisonment (or arrest) rate for Blacks is fairly consistent regardless of the percent Black, but the maximum rate has a fairly strong negative relation to the percent Black. The extraordinarily high Black imprisonment rates or disparities occur when the percent Black is small and the Black population in the area is also small, but the negative relation between percent Black and the maximum Black rate or disparity is consistent and strong for large Black populations.

This data pattern clearly suggests that the percent Black acts as a constraint on the maximum possible Black imprisonment or arrest rate. This is quite logical, as incarceration is extremely expensive and arrests are also expensive. Turning this around, it appears that having a small percent Black (approximately less than $20 \%$ ) is a necessary but not sufficient condition for having an exceptionally high Black imprisonment rate.

This very clear pattern has strong theoretical implications. The evidence strongly contradicts any simple one-actor "threat" model that posits social control response as a simple function of the percentage minority, 
whether that simple threat function is thought to be linear or curvilinear. The White majority may well feel threatened when a minority is large, but to act on that feeling with mass incarceration, they have to have the capacity to pay a very high price to feed and house prison inmates and do without them in the free labor market. Some sort of threat response may turn out to predict minority incarceration rates when the minority is small enough, but that threat is not any simple function of relative group size. The data clearly show that incarceration (and arrest) rates become more dispersed and more variable as the relative group size (percentage minority) decreases.

As we look for clues about the factors that predict mass incarceration, the results of this review suggest that these factors may be most operative when the percent minority is below $20 \%$.

\section{ADDENDUM: WHAT ABOUT OTHER RACIAL/ETHNIC GROUPS?}

If theoretical arguments about the impact of minority group size are to be seen as generally true, it is reasonable to wonder whether they apply to other ethnic minorities as well. In the 1980s and 1990s, the second largest ethnic group were Hispanics; Native people and Asians were overall small minorities who have large representation in some states. All three groups are even more concentrated than Blacks are into just a few states. Asians are unusual in that their incarceration rates are generally lower than Whites. Hispanics and Native people overall have incarceration rates that are intermediate between Blacks and Whites. Each of these groups has a peculiar situation that makes their comparison to Blacks problematic.

As Figure 22 for the rate and Figure 23 for disparity indicate, the pattern for Hispanics is similar to that for Blacks in exhibiting high variability at the low percent Hispanic end and more consistently moderate rates for the few states with high percentage Hispanic. However, the correlations between the Hispanic population proportion and the rate and disparity are essentially zero. The Hispanic incarceration rate a strong predictor of the Hispanic/White disparity (see Figure 24), accounting for 67\% of the variance in both decades 1993-1998. This is true even though the relation between the White rate and the Hispanic/White disparity (Figure 25) is similar for to the pattern seen for Blacks. Comparisons between Blacks and Hispanics are often problematic. Hispanics are racially diverse; half self-identify as White. Hispanics are counted as White in official arrest statistics and are often counted as White in prison statistics. Some states in some years consistently count Hispanics as "other race," while 
in other states and other years they are allocated to other racial groups, usually White. Further, immigrant Hispanics (both legal and illegal) are often deported rather than imprisoned. These factors mean that the rates for Hispanics cannot validly be compared to Blacks or Whites. ${ }^{9}$

The pattern for Native people is quite different, as Figure 26 shows. Alaska, the state with the highest Native population proportion, also has a very high Native incarceration rate, while states with very few Native people often report no Native prisoners at all. Between these extremes there appears to be no particular relation between minority group proportion and the imprisonment rate. Imprisonment statistics for Native people also cannot be validly compared to Blacks or Whites. Half of Native people live on reservations where some crimes automatically go to federal court rather than state court, as they would for people who do not live on reservations. Further, tribal courts handle many lesser offenses. This means that state prisons house a smaller proportion of Native inmates than for other racial groups. Also, Native people living in places where there are few Native people are often mistakenly counted as White in criminal justice statistics.

For Asians, the only real pattern is that Hawaii, which is $60 \%$ Asian and has an Asian population that is disproportionately not immigrant, has the highest Asian incarceration rate (see Figure 27) and that no Asians are reported as imprisoned in many states with small Asian populations. Otherwise, Asian incarceration rates are unrelated to percent Asian. However, digging into the Hawaiian pattern is instructive. Hawaii is often noted for having the lowest Black/White disparity in the nation, but it turns out this is because Whites are not the mostadvantaged group in Hawaii when it comes to imprisonment. From 2000 on, we have information to distinguish Pacific Islanders from Asians. These are normally grouped together because there are too few Pacific Islanders for separate analysis. Hawaii is the exception, however. Ninety percent of the Pacific Islander population lives in Hawaii; most of these are native Hawaiians, who are disadvantaged relative to the majority population. Others are from other US possessions in the Pacific and are also disadvantaged. When Asians are distinguished from Pacific Islanders, as they are in Figure 28, Asians have the lowest imprisonment rates in Hawaii. In fact, their rates are even significantly lower than the White rates: the White/Asian disparity averaged a little over 2 . The Hispanic/Asian disparity was just a little over 1; it is not clear why it is lower than the White/Asian disparity unless tourism is a factor. The Black/Asian disparity was about 4. But the Hawaiian disparity in imprisonment for Pacific 
Islanders relative to Asians was about 11 to $1 !^{10}$ Although this book is about the Black and White racial patterns, this pattern highlights the importance of looking at the political and social hierarchies in each place.

Overall, then, despite sound theoretical reasons that can account for the tendency for Black incarceration to be moderated in the states with large Black population proportions and the longstanding character of this pattern for Blacks, we do not find a similar pattern for other ethnic minorities. The only pattern that is consistent across ethnic groups is that incarceration rates are much more variable when the population proportion is small.

\section{Methodological Addendum: Representativeness of NCRP states}

Most of the analysis in this book is restricted to the 25 states for which we had relatively complete information from the National Corrections Reporting Program (NCRP) for 1985-2002. For this reason, it is helpful to look at the scatter plots showing the CPUS rates by the percent Black for the NCRP and non-NCRP states. Figure 29 shows the black rate, Figure 30 the Black/White disparity and Figure 31 the White rate of the CPUS imprisonment rate. The figures show that the impact of the Black population proportion is stronger in the NCRP sample than in the full set of states because the non-NCRP states are disproportionately those with low Black/White rates and disparities and low percent Black. The big losses for a study of the racial dynamics of incarceration include Texas, Florida, Maryland, Louisiana and Tennessee, which have some NCRP data on total prison admissions but inadequate information for breaking the admissions down by offense, type, or sub-state region. In addition, some of the area classifications in North Carolina are problematic in the late 1990s. 


\section{REFERENCES}

Arvanites, Thomas M. 1997. "The Direct and Indirect Effects of Race and Poverty on County Incarceration Rates." Journal of Crime and Justice 20:87-102.

Arvanites, Thomas M., and Martin A. Asher. 1998. "State and County Incarceration Rates: The Direct and Indirect Effects of Race and Inequality." American Journal of Economics and Sociology 57:207-21.

Blalock, Hubert M. 1967. Toward a Theory of Minority-Group Relations. New York: Wiley.

Blumstein, Alfred. 1982. "On the Racial Disproportionality of United States' Prison Populations." Journal of Criminal Law and Criminology 73(3):1.

—. 1993. "Racial Disproportionality of U.S. Prison Populations Revisited." University of Colorado Law Review 64:743.

Bridges, George S., and Robert D. Crutchfield. 1988. "Law, Social Standing and Racial Disparities in Imprisonment." Social Forces 66:699-724.

Christianson, Scott. 1981. "Our Black Prisons." Crime and Delinquency 27(3):364-75.

Crawford, Charles, Theodore G. Chiricos, and Gary Kleck. 1998. "Race, racial threat, and sentencing of habitual offenders." Criminology 36(3):481-511.

DeLisi, Matt, and Bob Regoli. 1999. "Race, Conventional Crime, and Criminal Justice: The Declining Importance of Skin Color." Journal of Criminal Justice 27(6):549-57.

Greenberg, David F., and Valerie West. 2001. "State prison populations and their growth, 19711991." Criminology 39(3):615-53.

Hawkins, Darnell F., and Kenneth A. Hardy. 1989. "Black-White Imprisonment Rates: A State-byState Analysis." Social Justice 16( 4(38), winter):75-94.

Jacobs, David, and Jason T. Carmichael. 2001. "The Politics of Punishment across Time and Space: A Pooled Time-Series Analysis of Imprisonment Rates." Social Forces 80(1):61-89.

Keen, Bradley, and David Jacobs. 2009. "RACIAL THREAT, PARTISAN POLITICS, AND RACIAL DISPARITIES IN PRISON ADMISSIONS: A PANEL ANALYSIS." Criminology 47(1):209-38.

Langan, Patrick A. 1991. "America's Soaring Prison Population." Science 251(5001):1568-73.

Oliver, Pamela E. 2008. "Regionalism and Percent Black: Trends 1926-1982." in available at http://ssc.wisc.edu/ oliver/RACIAL/Reports/Regionalism\%20and\%20Percent\%20Black\% 20Historical\%20Trends\%201926-82.pdf.

Oliver, Pamela E., and James E. Yocom. 2004. "Explaining State Black Imprisonment Rates 19831999." in American Sociological Association. San Francisco.

Stein Lee, Yetta. 2001. "The psychosocial needs of Hawaiian women incarcerated for drugrelated crimes." Journal of Social Work Practice in the Addictions 1(4):47-69.

Yates, Jeff. 1997. "Racial Incarceration Disparity among States." Social Science Quarterly (University of Texas Press) 78(4):1001-10. 
List of Figures

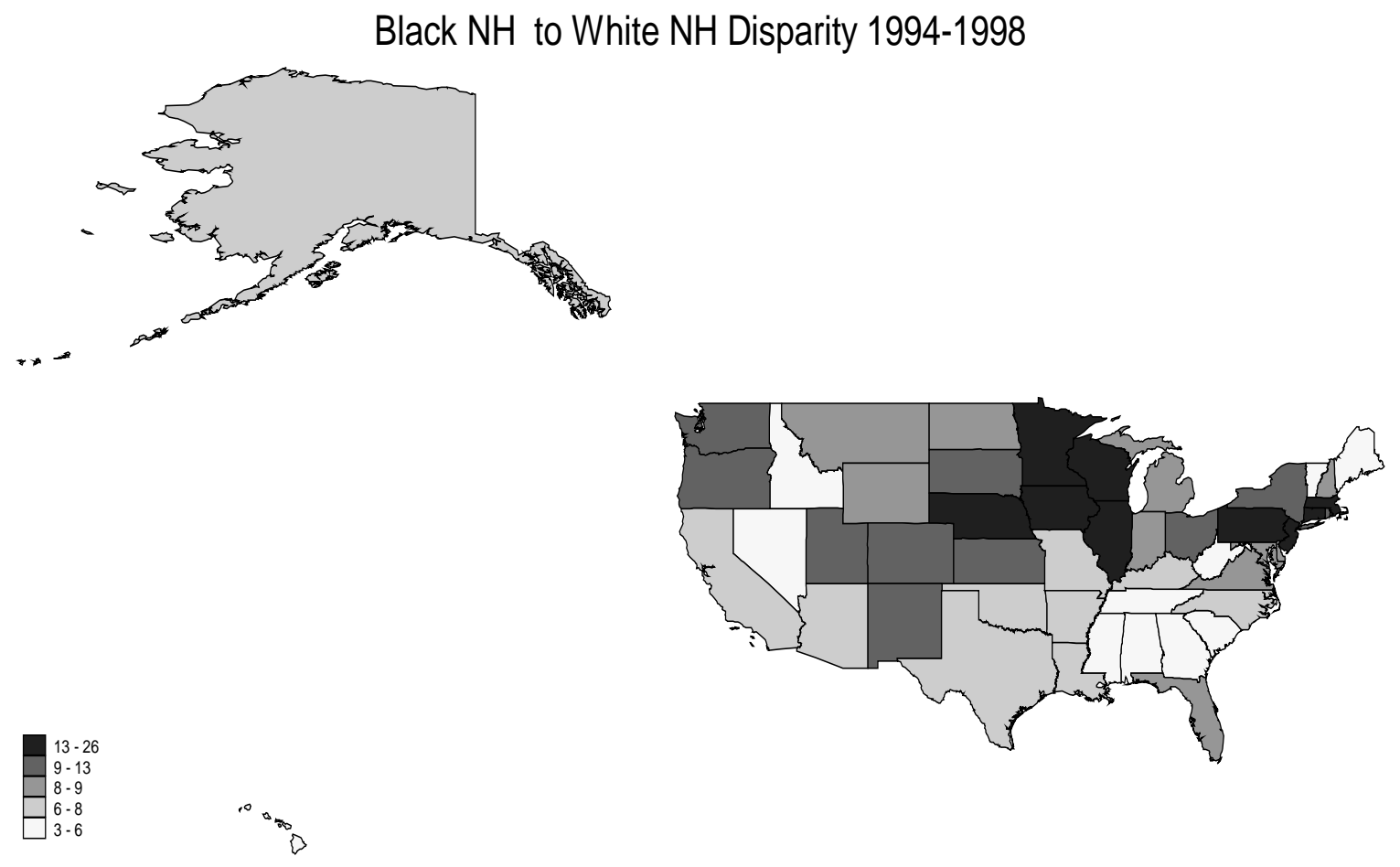

FIGURE 1. BLACK/WHITE DISPARITY IN US STATES 1994-1998 (MAP) 


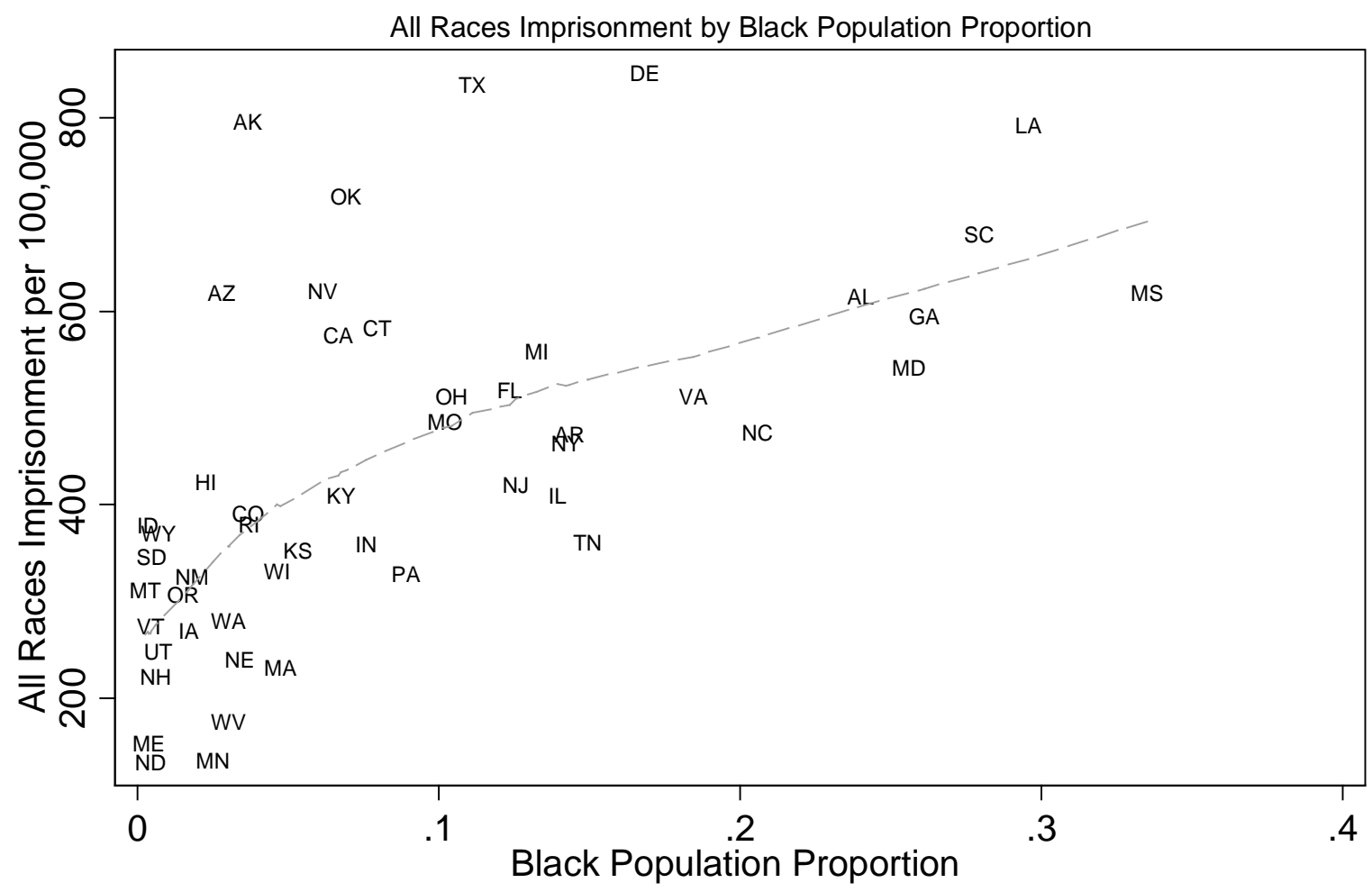

Correlation $=.59 ; \mathrm{r} 2=.35$.

1993-1998

FIGURE 2. ALL RACES IMPRISONMENT RATE BY BLACK POPULATION PROPORTION 1993-1998 


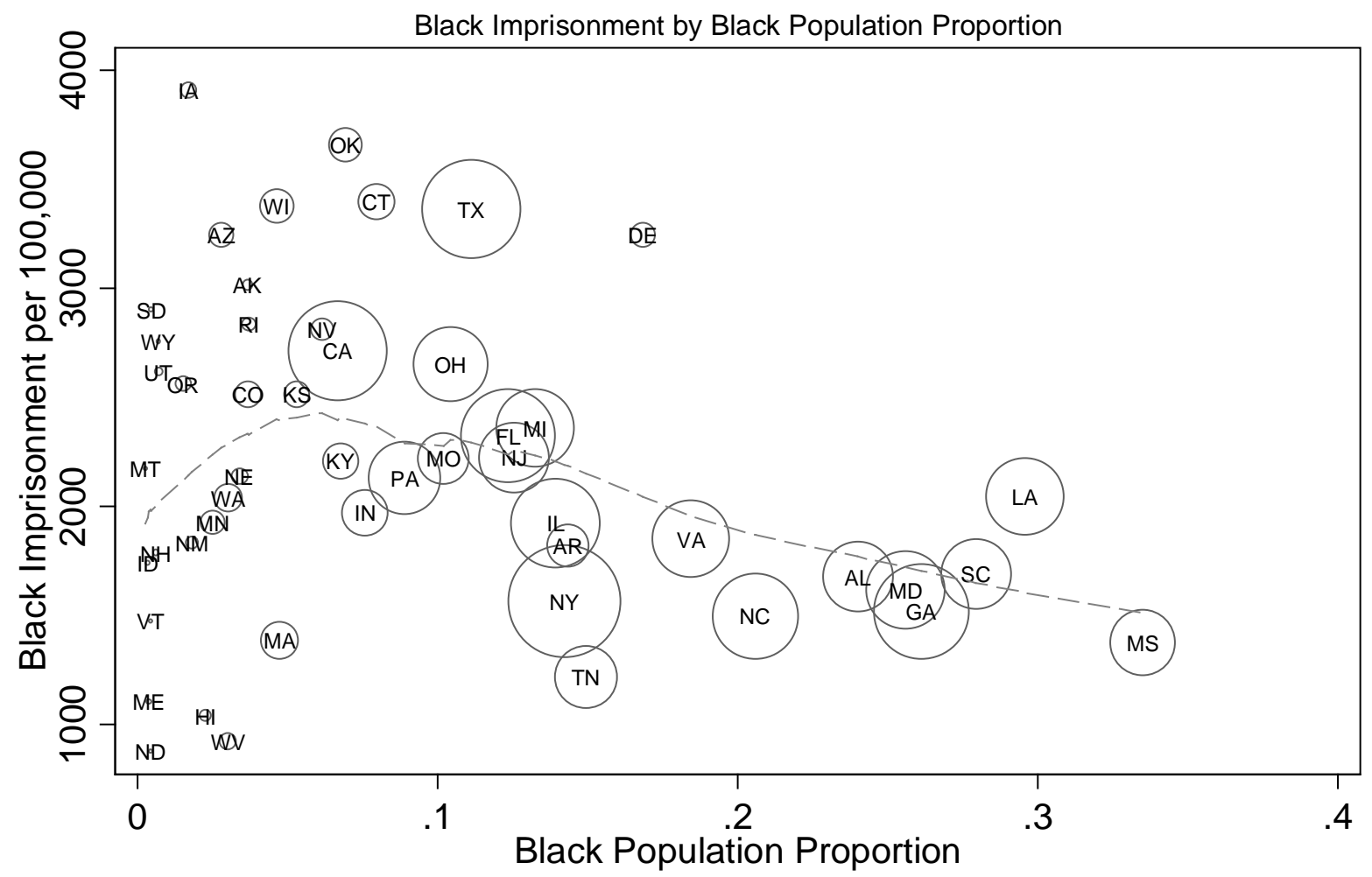

Correlation $=-.21 ; \mathrm{r} 2=.05$. Weighted by Black Population

1993-1998

FIGURE 3. BLACK IMPRISONMENT BY BLACK POPULATION PROPORTION 1993-1998 


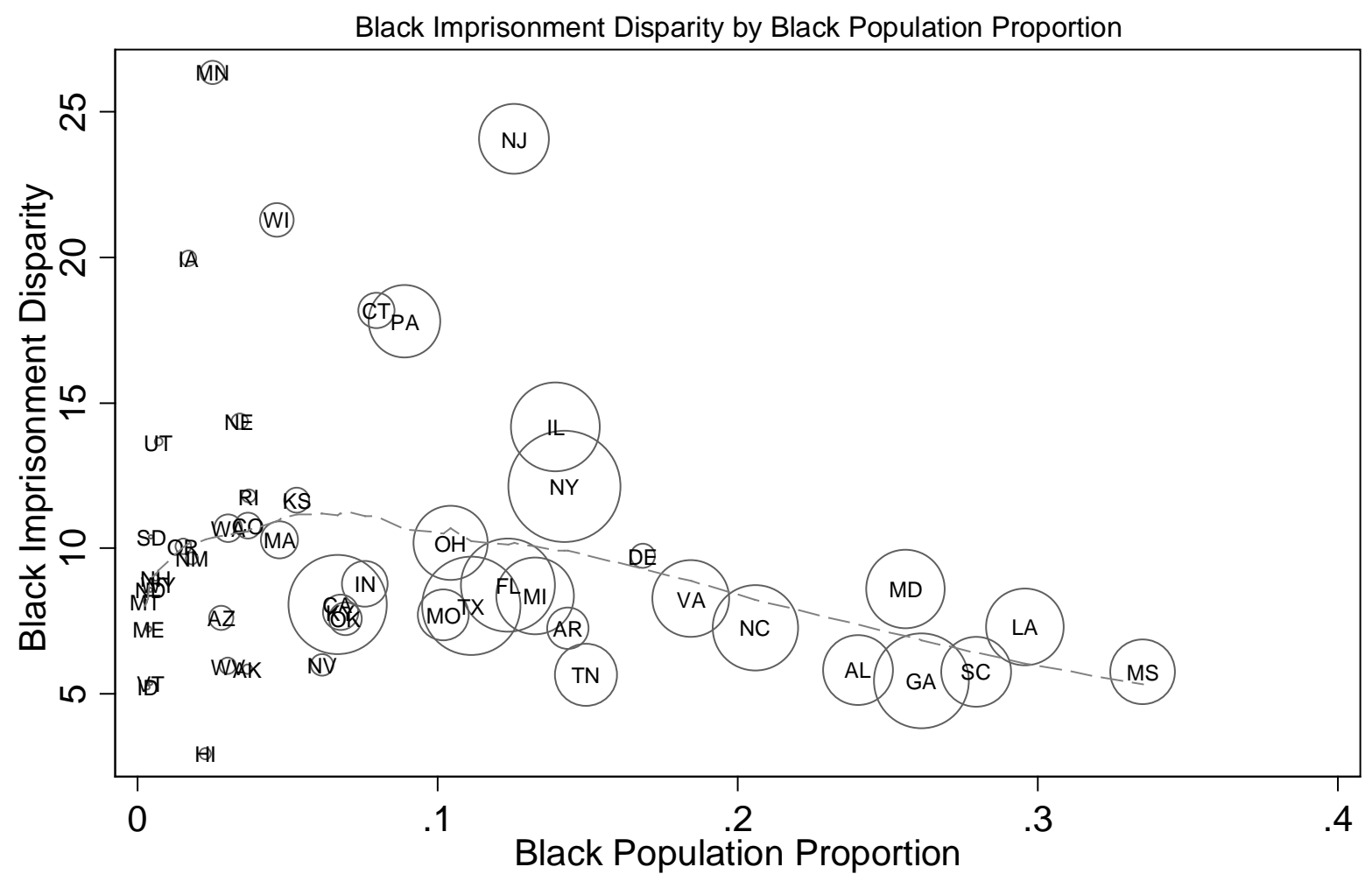

Correlation $=-.21 ; \mathrm{r} 2=.05$. Weighted by Black Population

1993-1998

FIGURE 4. BLACK IMPRISONMENT DISPARITY BY BLACK POPULATION PROPORTION 1993-1998 


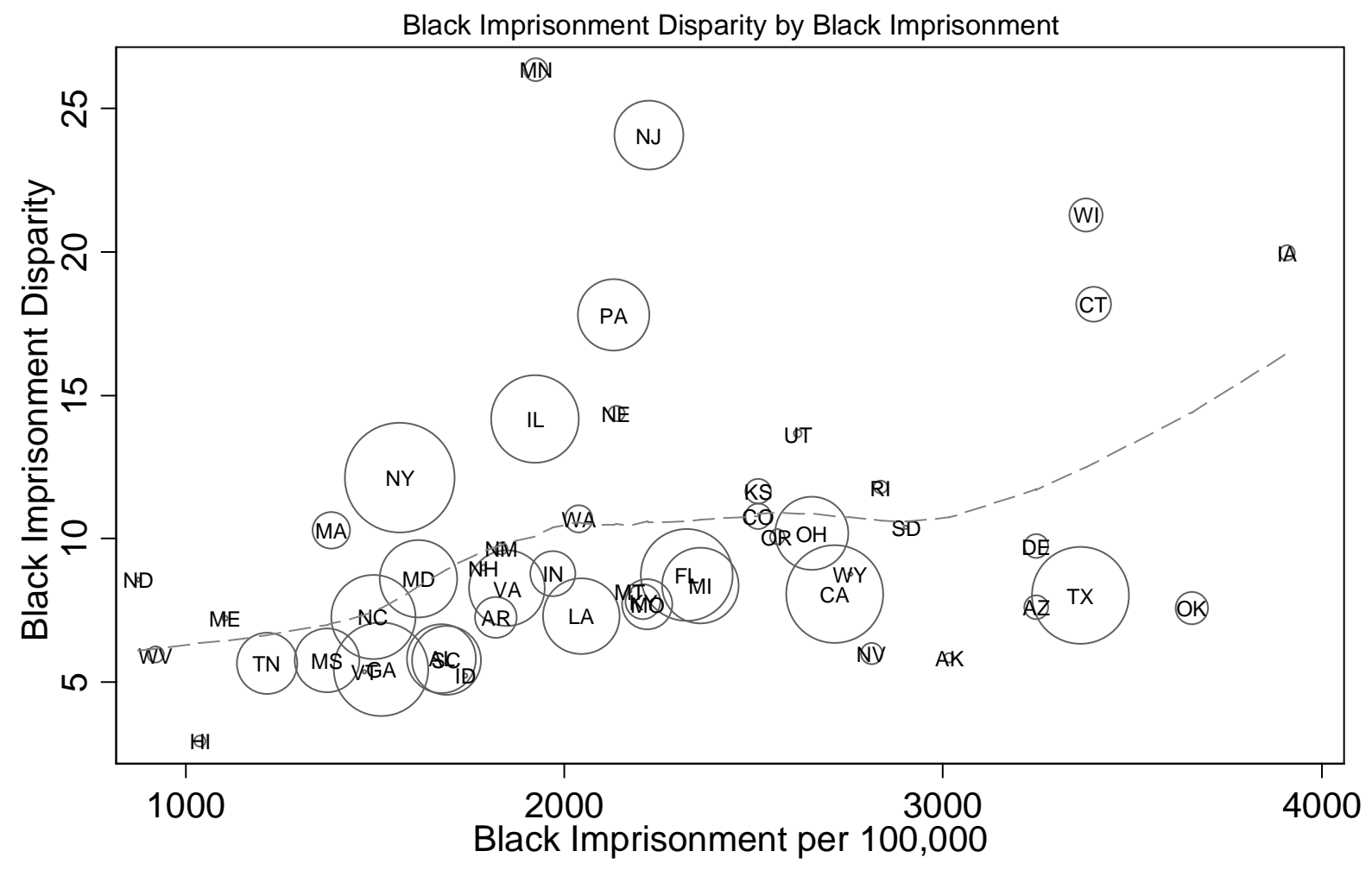

Correlation $=.35 ; \mathrm{r} 2=.12$. Weighted by Black Population

1993-1998

FIGURE 5. BLACK IMPRISONMENT DISPARITY BY BLACK IMPRISONMENT RATE 1993-1998 


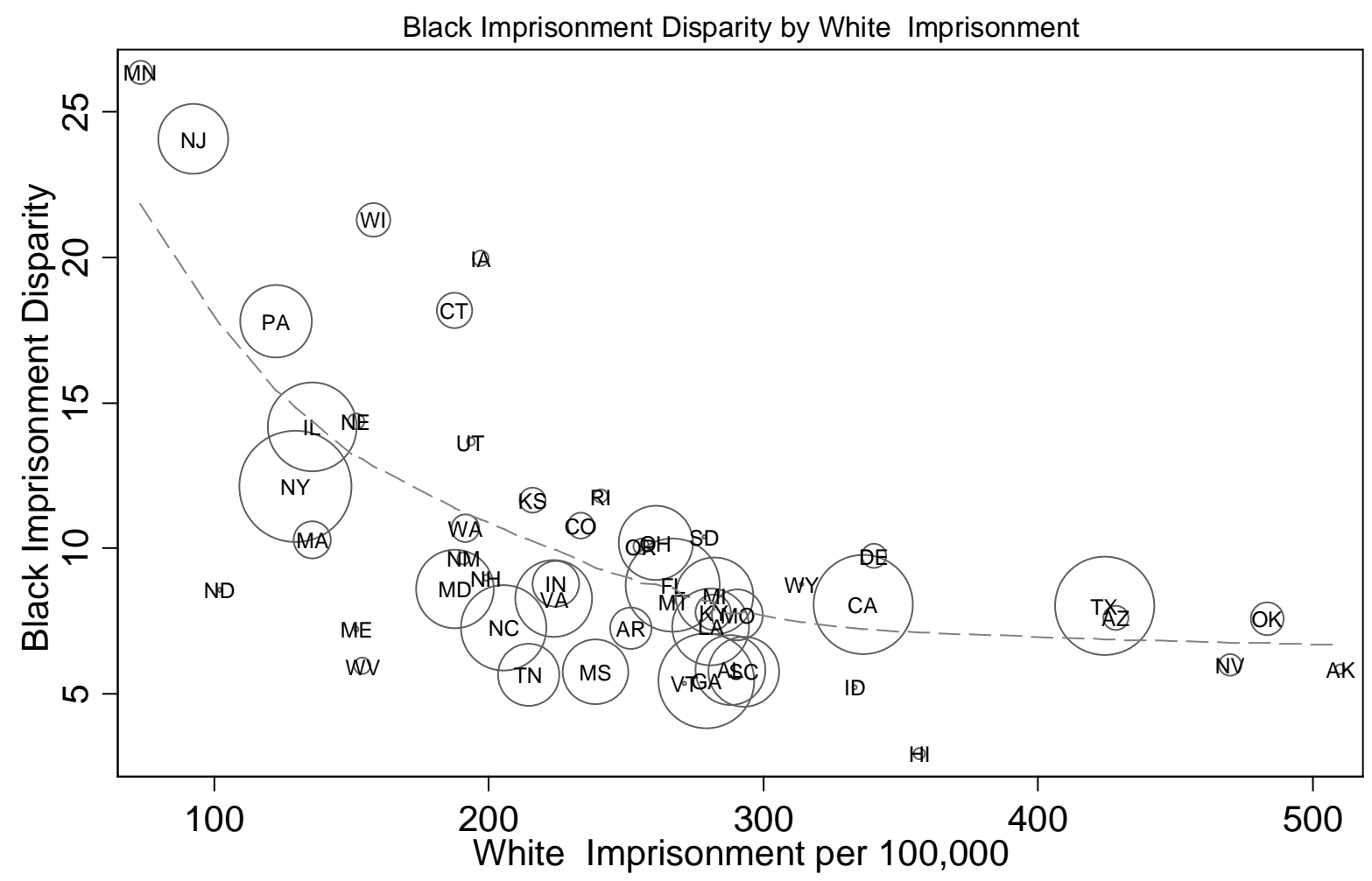

Correlation=-.56; r2=.31. Weighted by Black Population

1993-1998

FIGURE 6. BLACK IMPRISONMENT DISPARITY BY WHITE IMPRISONMENT RATE 1993-1998 
White Imprisonment by Black Population Proportion

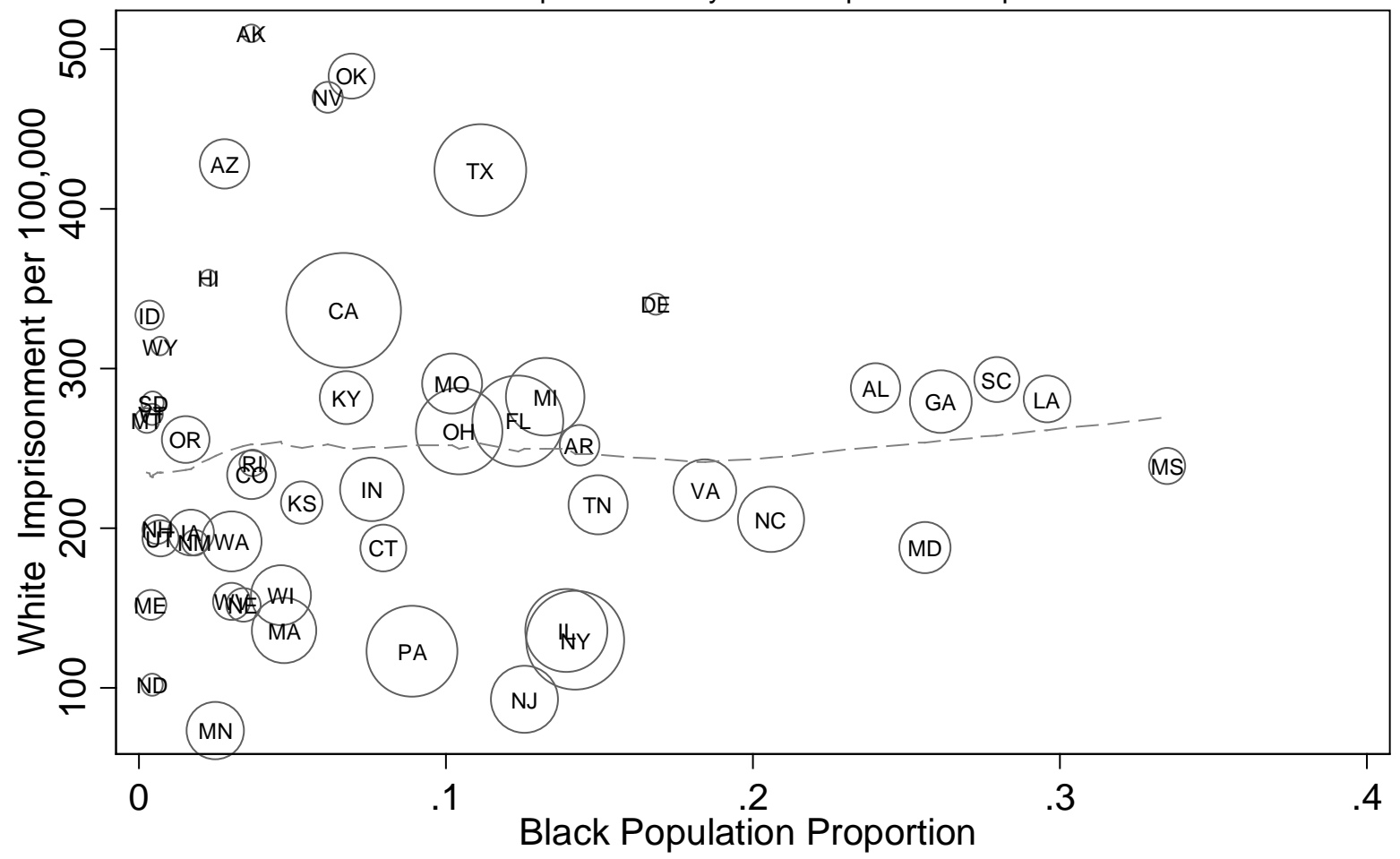

Correlation $=.03 ; \mathrm{r} 2=0$. Weighted by White Population

1993-1998

FIGURE 7. WHITE IMPRISONMENT RATE BY BLACK POPULATION PERCENTAGE 1993-1998 
White Imprisonment by White Population Proportion

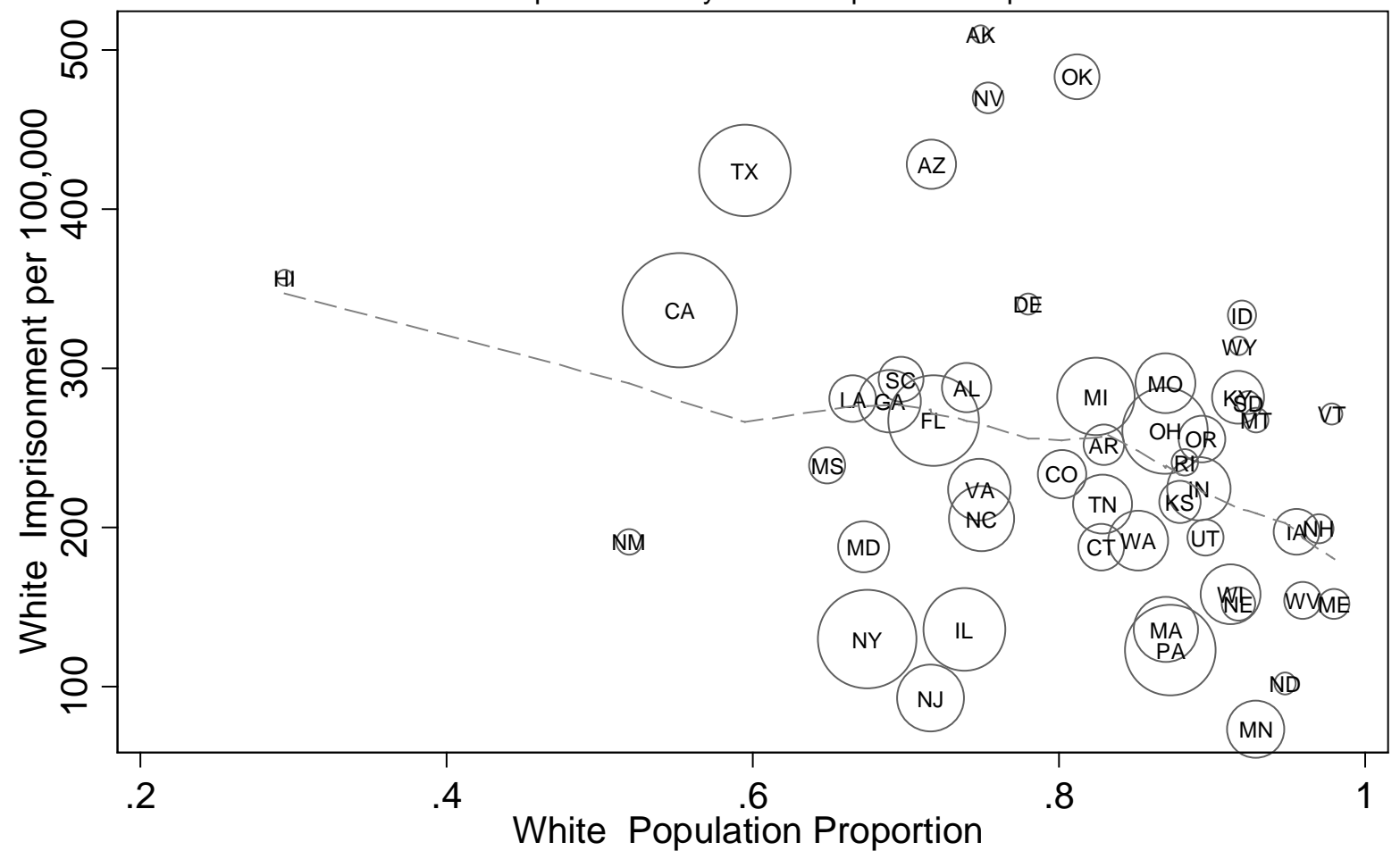

Correlation=-.32; r2=.1. Weighted by White Population

1993-1998

FIGURE 8. WHITE IMPRISONMENT RATE BY WHITE POPULATION PERCENTAGE 1993-1998 
White Imprisonment by White Proportion Urban

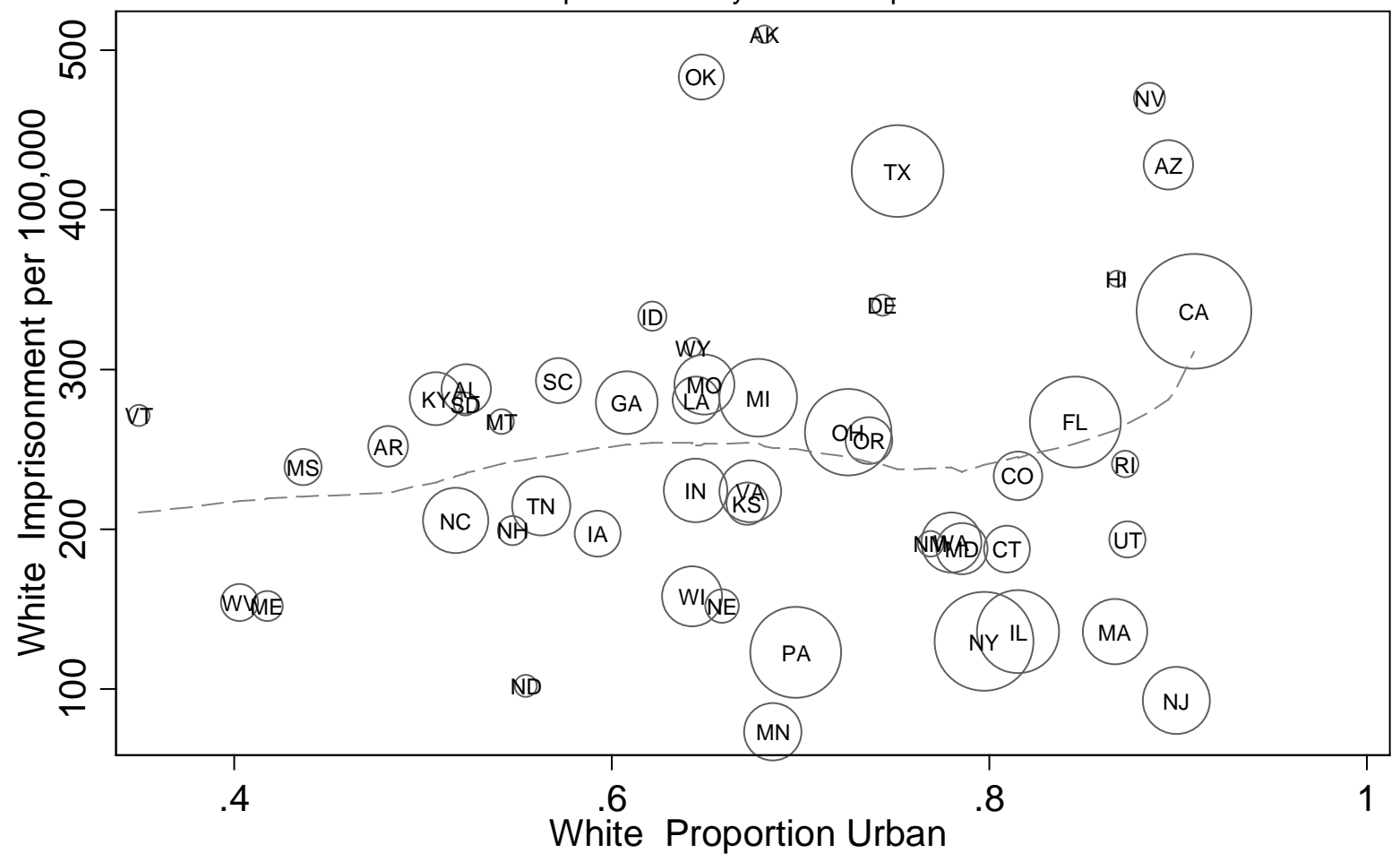

Correlation $=.1 ; \mathrm{r} 2=.01$. Weighted by White Population 1993-1998

FIGURE 9. WHITE IMPRISONMENT RATE BY WHITE PROPORTION URBAN 1993-1998 


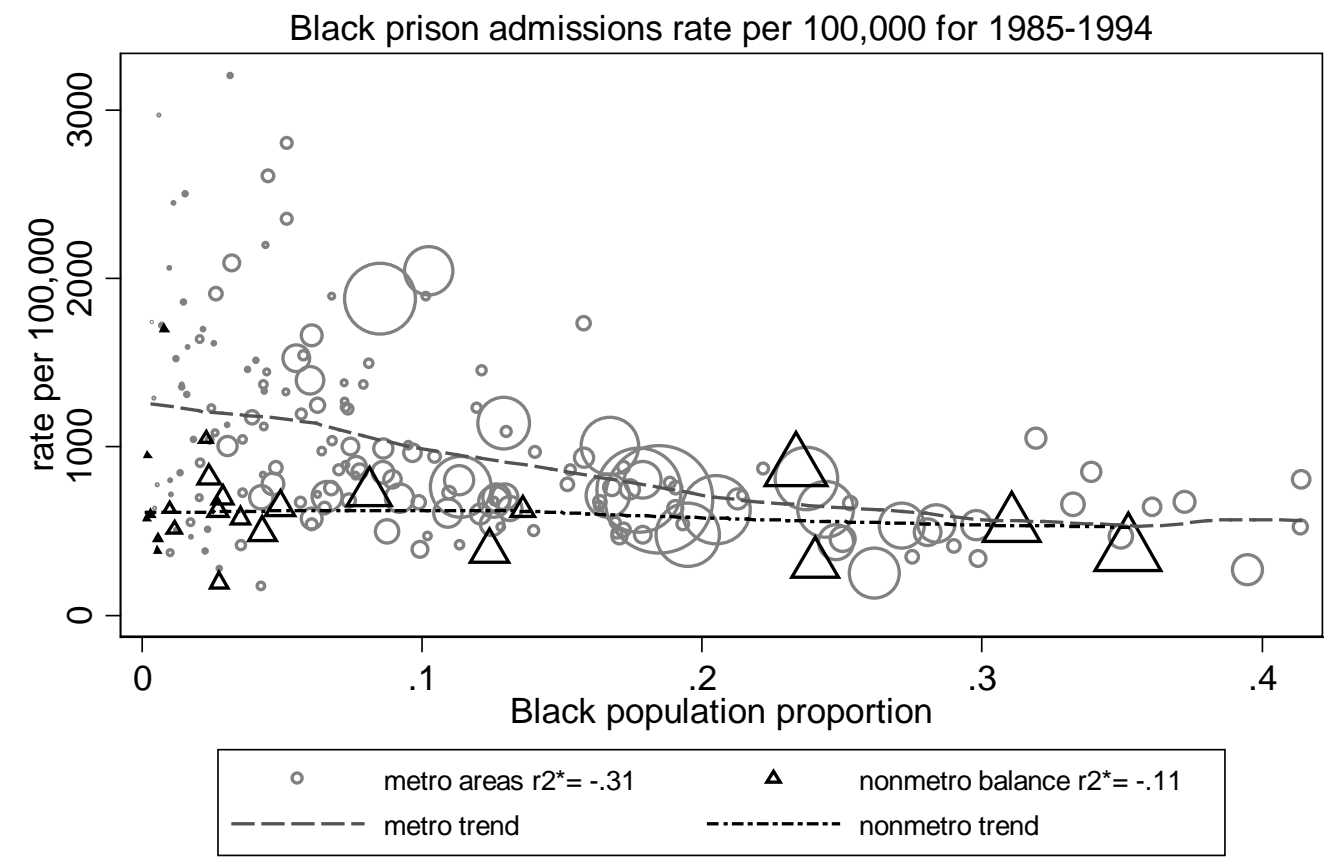

194 areas with complete prison data. Weighted by Black population $\mathrm{r} 2^{\star}$ is signed R2

FIGURE 10. BLACK PRISON ADMISSIONS, METRO AND NONMETRO AREAS 1985-1994 


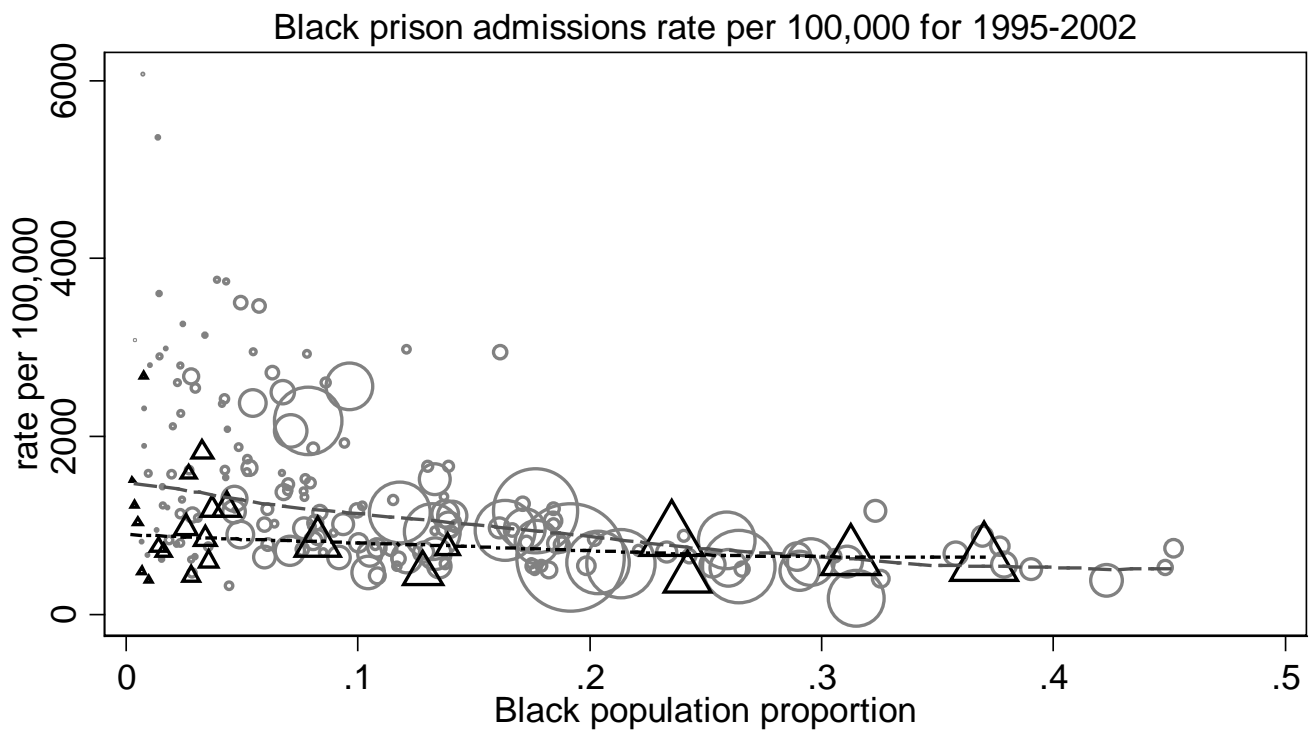

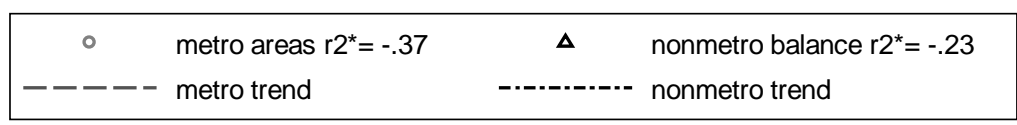

194 areas with complete prison data. Weighted by Black population $\mathrm{r} 2^{\star}$ is signed R2

FIGURE 11. BLACK PRISON ADMISSIONS, METRO AND NONMETRO AREAS 1995-2002 


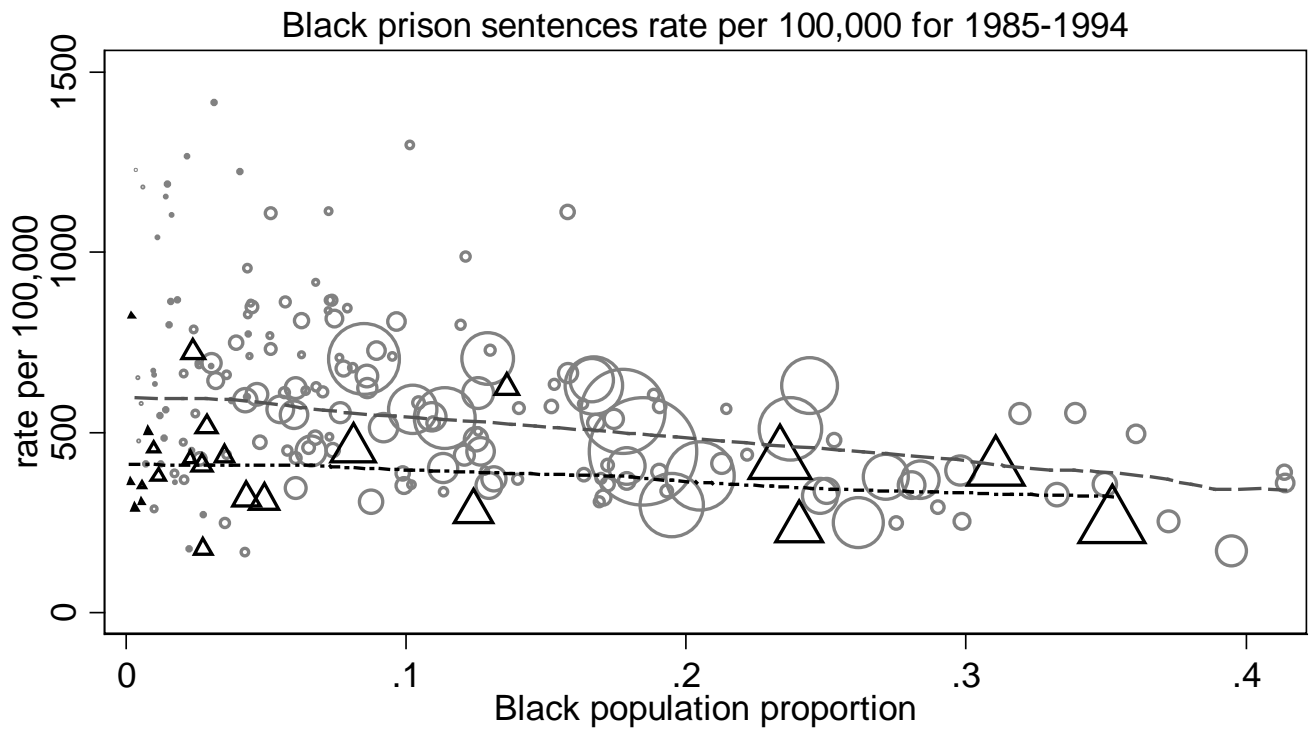

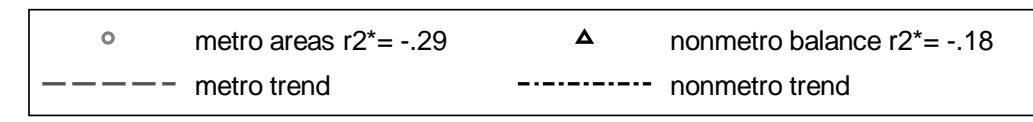

194 areas with complete prison data. Weighted by Black population $\mathrm{r} 2^{\star}$ is signed R2

FIGURE 12. BLACK NEW SENTENCES, METRO AND NONMETRO AREAS 1985-1994 


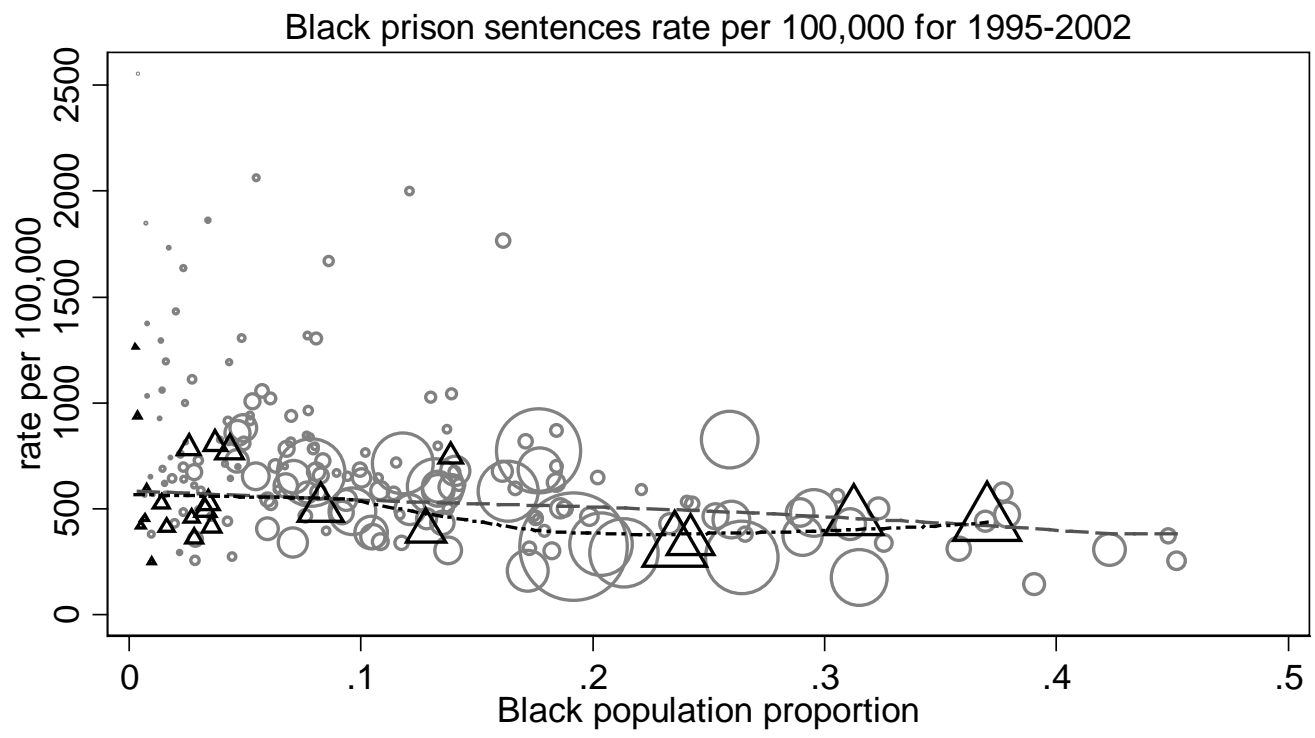

\begin{tabular}{|c|c|c|c|}
\hline$\circ$ & metro areas $r 2^{*}=-.22$ & $\Delta$ & nonmetro balance $\mathrm{r} 2^{*}=-.19$ \\
\hline -ーーーー & metro trend & -・-・-・-- & nonmetro trend \\
\hline
\end{tabular}

194 areas with complete prison data. Weighted by Black population $\mathrm{r} 2^{\star}$ is signed R2

FIGURE 13. BLACK NEW SENTENCES, METRO AND NONMETRO AREAS 1995-2002 


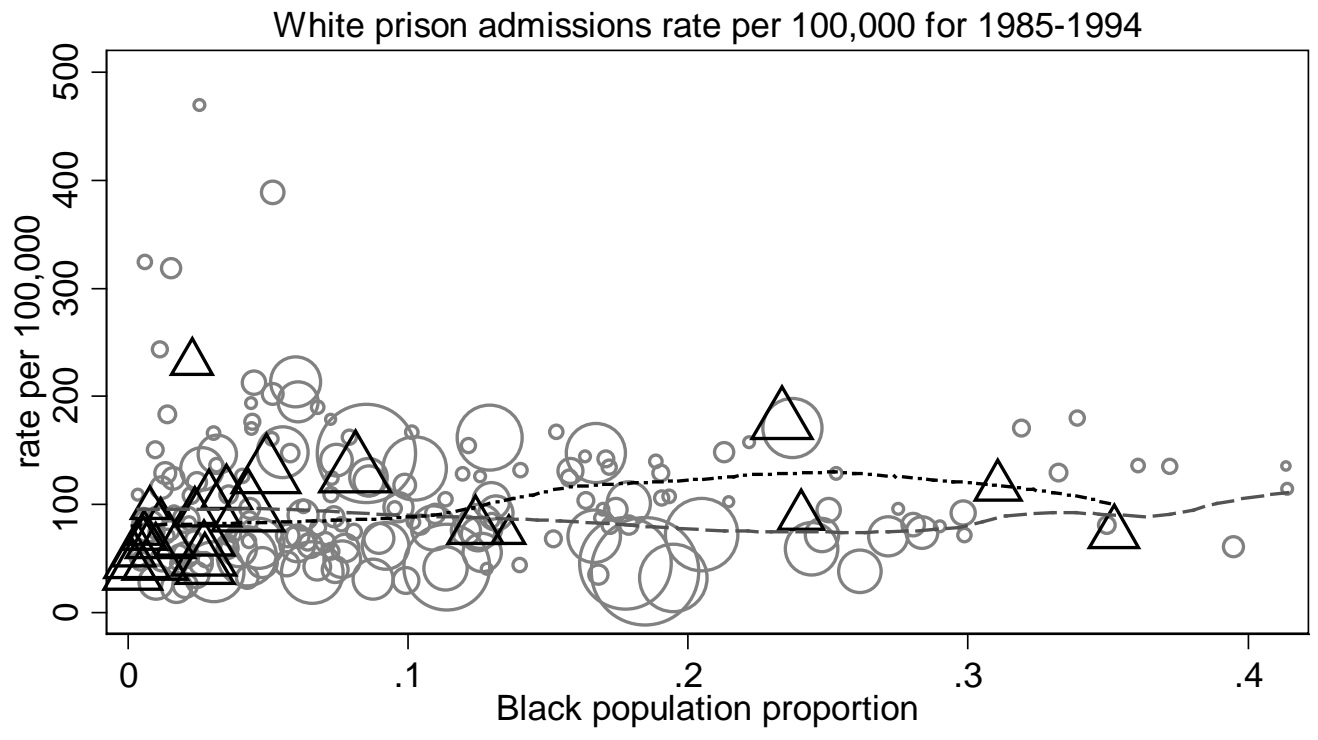

\begin{tabular}{|clll|}
\hline 0 & metro areas $\mathrm{r}^{*}=-.02$ & $\Delta$ & nonmetro balance $\mathrm{r}^{*}=.13$ \\
----- & metro trend & $-\cdots$ & nonmetro trend \\
\hline
\end{tabular}

194 areas with complete prison data. Weighted by White population $\mathrm{r} 2^{\star}$ is signed R2

FIGURE 14. WHITE PRISON ADMISSIONS, METRO AND NONMETRO AREAS 1985-1994 


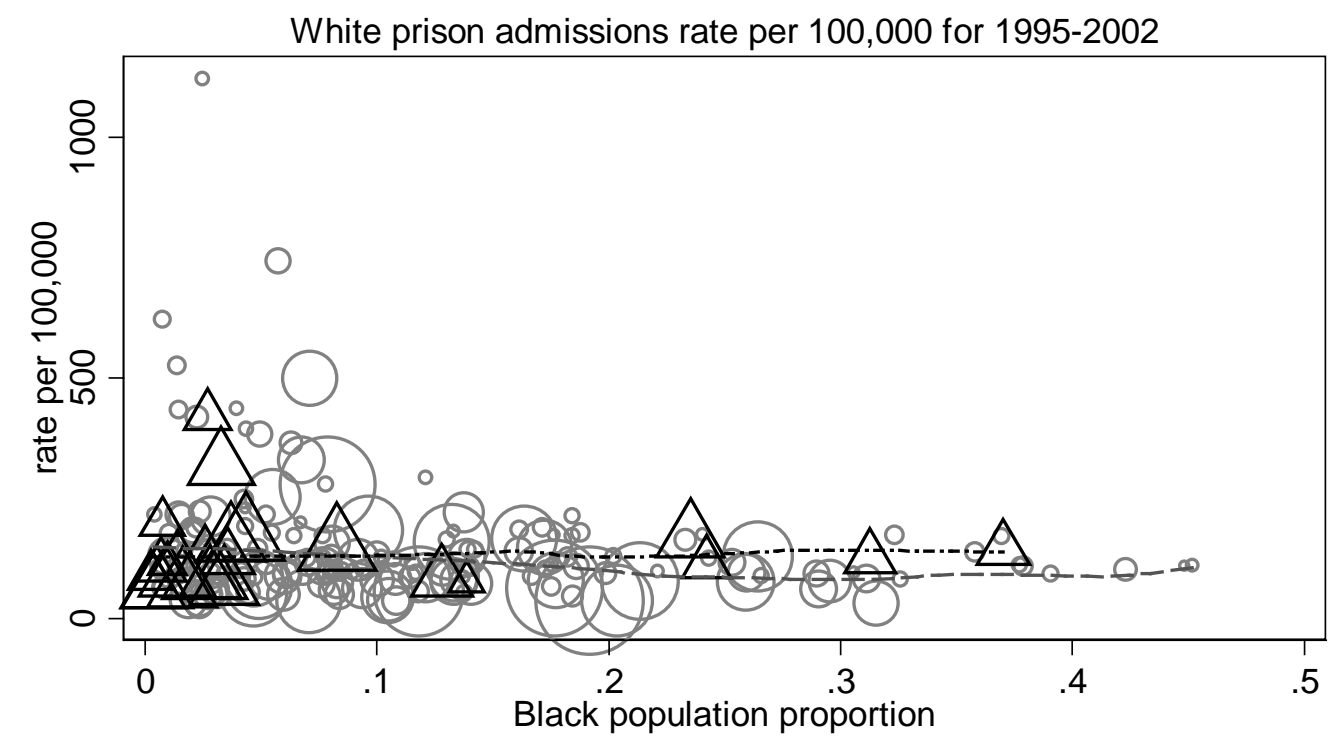

\begin{tabular}{|clcl|}
\hline 0 & metro areas $\mathrm{r}^{*}=-.07$ & $\Delta$ & nonmetro balance $\mathrm{r}^{*}=.01$ \\
----- & metro trend & $-\cdots$ & nonmetro trend \\
\hline
\end{tabular}

194 areas with complete prison data. Weighted by White population $\mathrm{r} 2^{\star}$ is signed R2

FIGURE 15. WHITE PRISON ADMISSIONS, METRO AND NONMETRO AREAS 1995-2002 


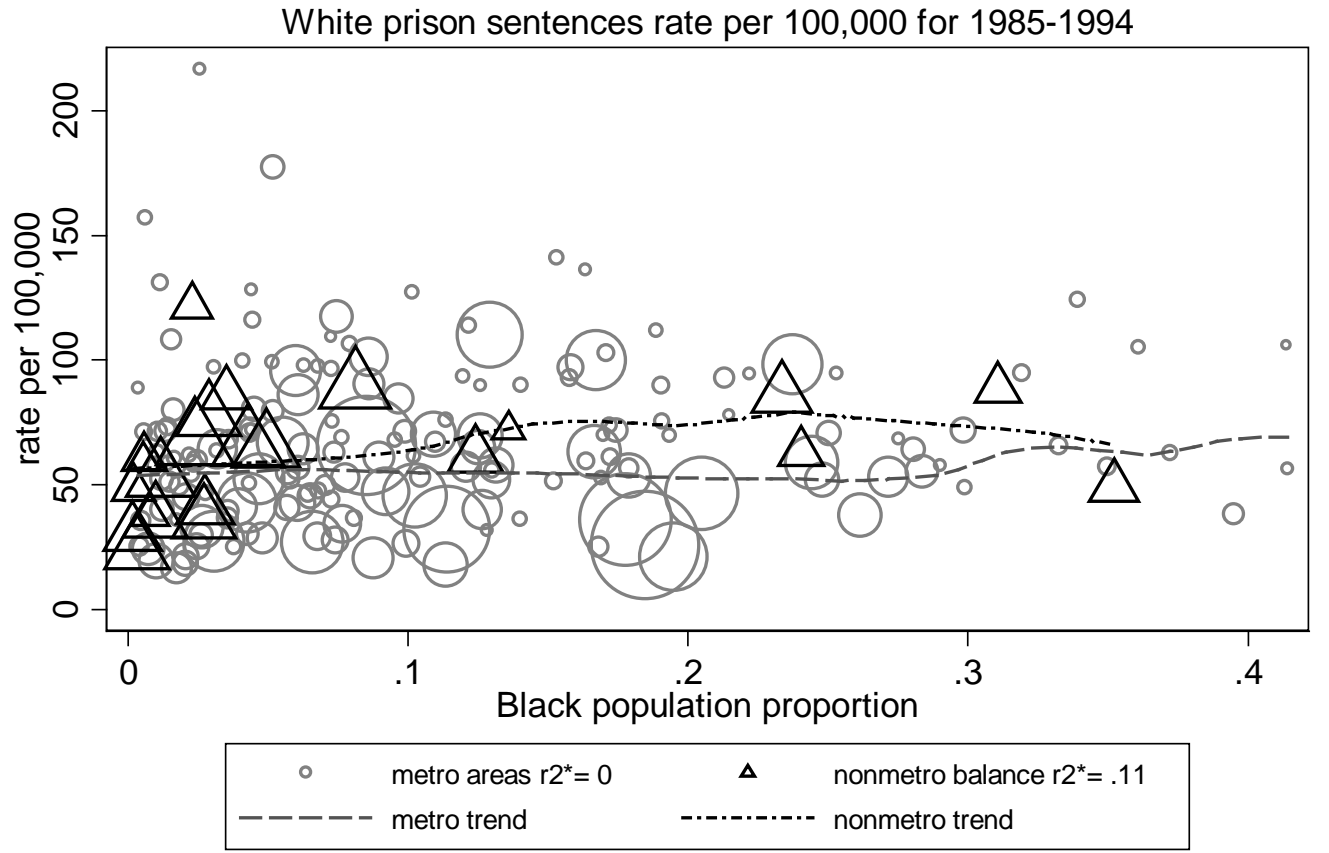

194 areas with complete prison data. Weighted by White population $\mathrm{r} 2^{\star}$ is signed R2

FIGURE 16. WHITE NEW SENTENCES, METRO AND NONMETRO AREAS 1985-1994 


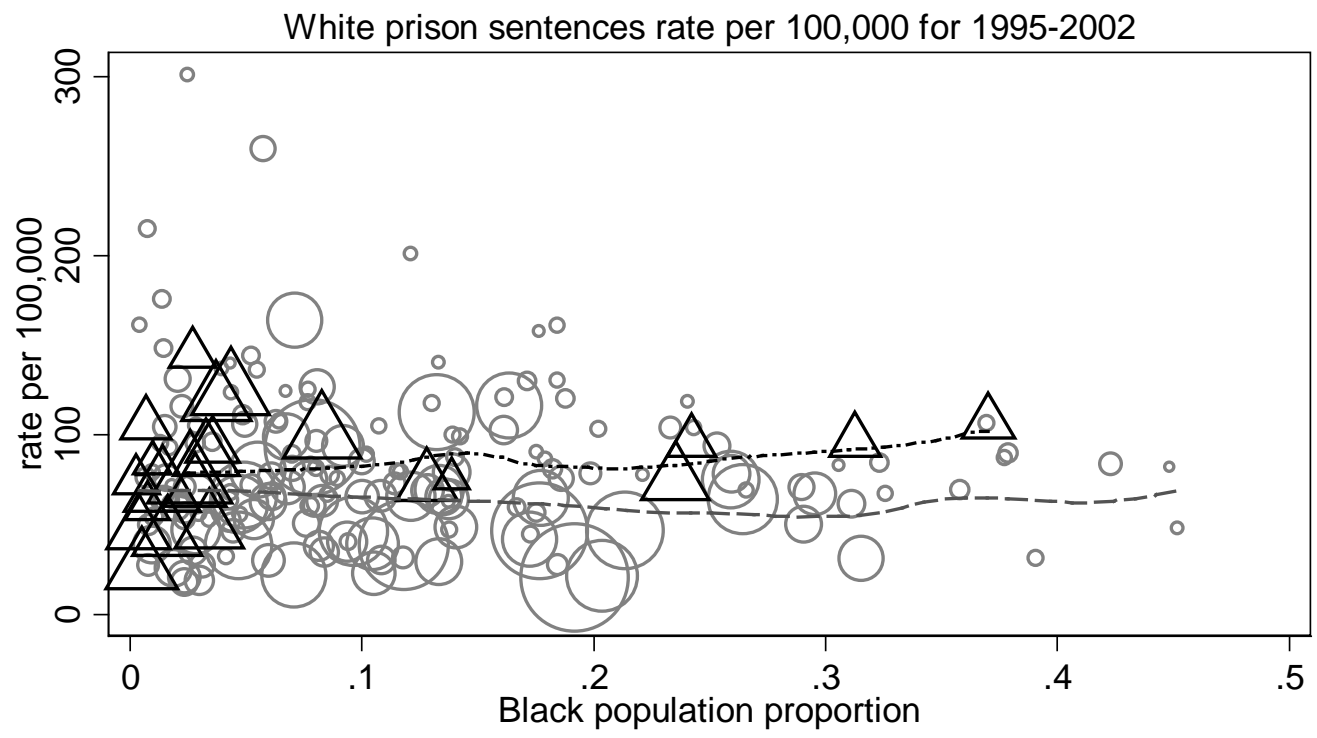

\begin{tabular}{|c|c|c|c|}
\hline$\circ$ & metro areas $r 2^{*}=-.02$ & $\Delta$ & nonmetro balance $r{ }^{*}=.07$ \\
\hline----- & metro trend & 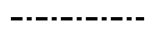 & nonmetro trend \\
\hline
\end{tabular}

194 areas with complete prison data. Weighted by White population $\mathrm{r} 2^{\star}$ is signed R2

FIGURE 17. WHITE NEW SENTENCES, METRO AND NONMETRO AREAS 1995-2002 


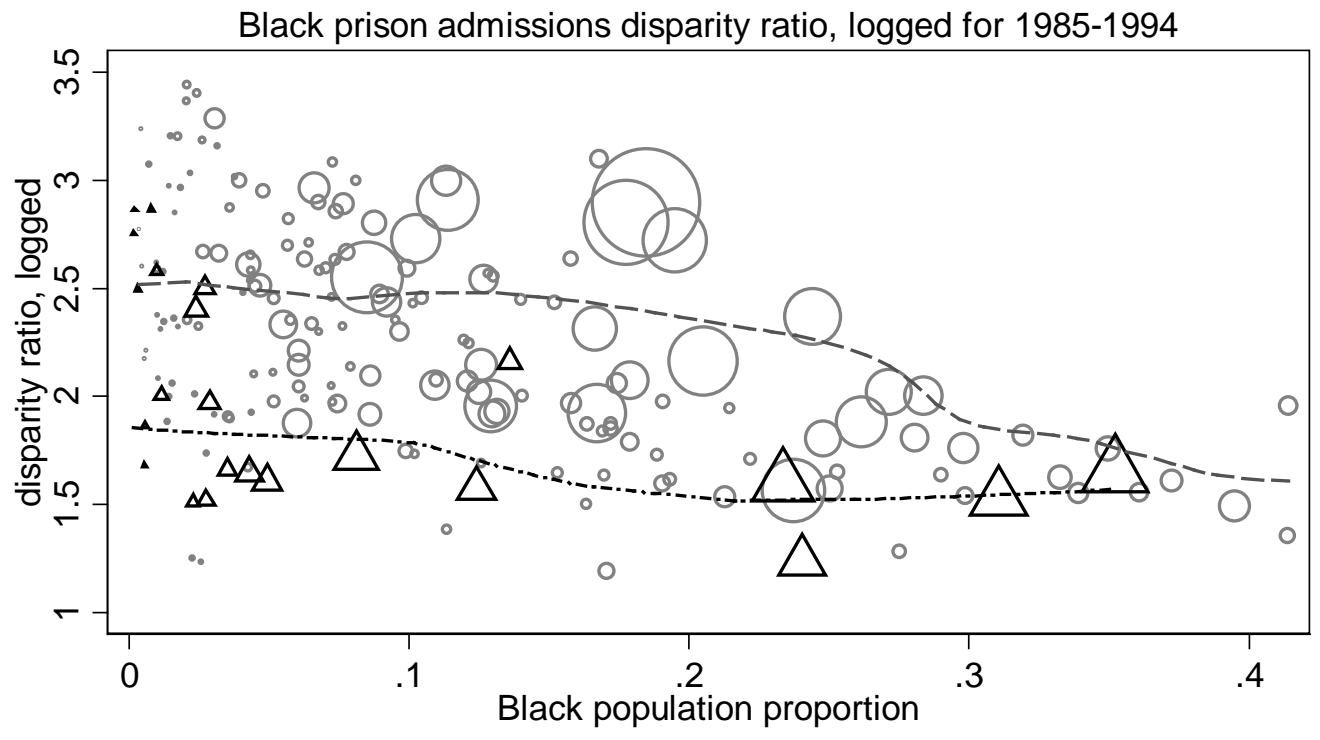

\begin{tabular}{|c|c|c|c|}
\hline $\begin{array}{c}\circ \\
-----\end{array}$ & $\begin{array}{l}\text { metro areas } \mathrm{r} 2^{*}=-.22 \\
\text { metro trend }\end{array}$ & $\begin{array}{c}\Delta \\
-\cdot-\cdot-\cdot--\end{array}$ & $\begin{array}{l}\text { nonmetro balance } r 2^{\star}=-.21 \\
\text { nonmetro trend }\end{array}$ \\
\hline
\end{tabular}

194 areas with complete prison data. Weighted by Black population $\mathrm{r} 2^{\star}$ is signed R2

FIGURE 18. BLACK PRISON ADMISSION DISPARITY, METRO AND NONMETRO AREAS 1985-1994 


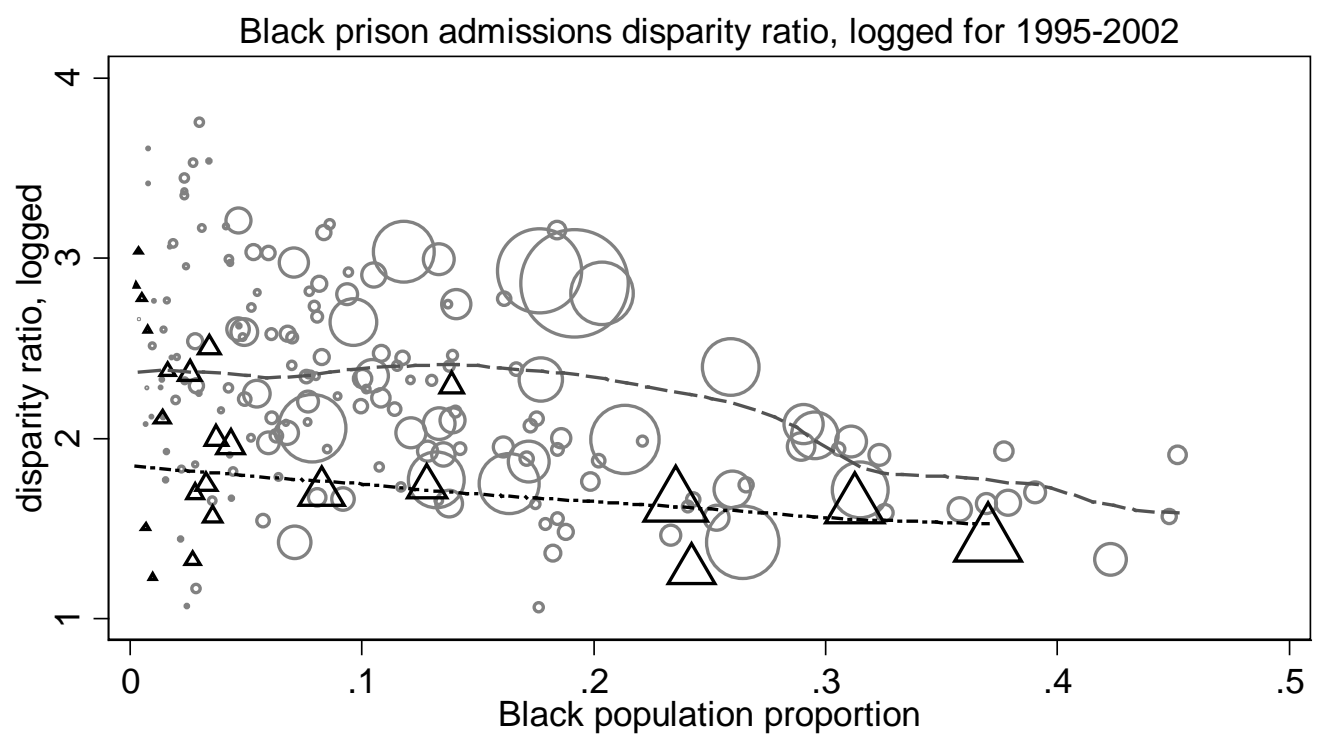

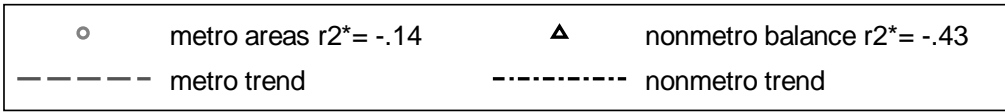

194 areas with complete prison data. Weighted by Black population $\mathrm{r} 2^{\star}$ is signed R2

FIGURE 19. BLACK PRISON ADMISSION DISPARITY, METRO AND NONMETRO AREAS 1995-2002 


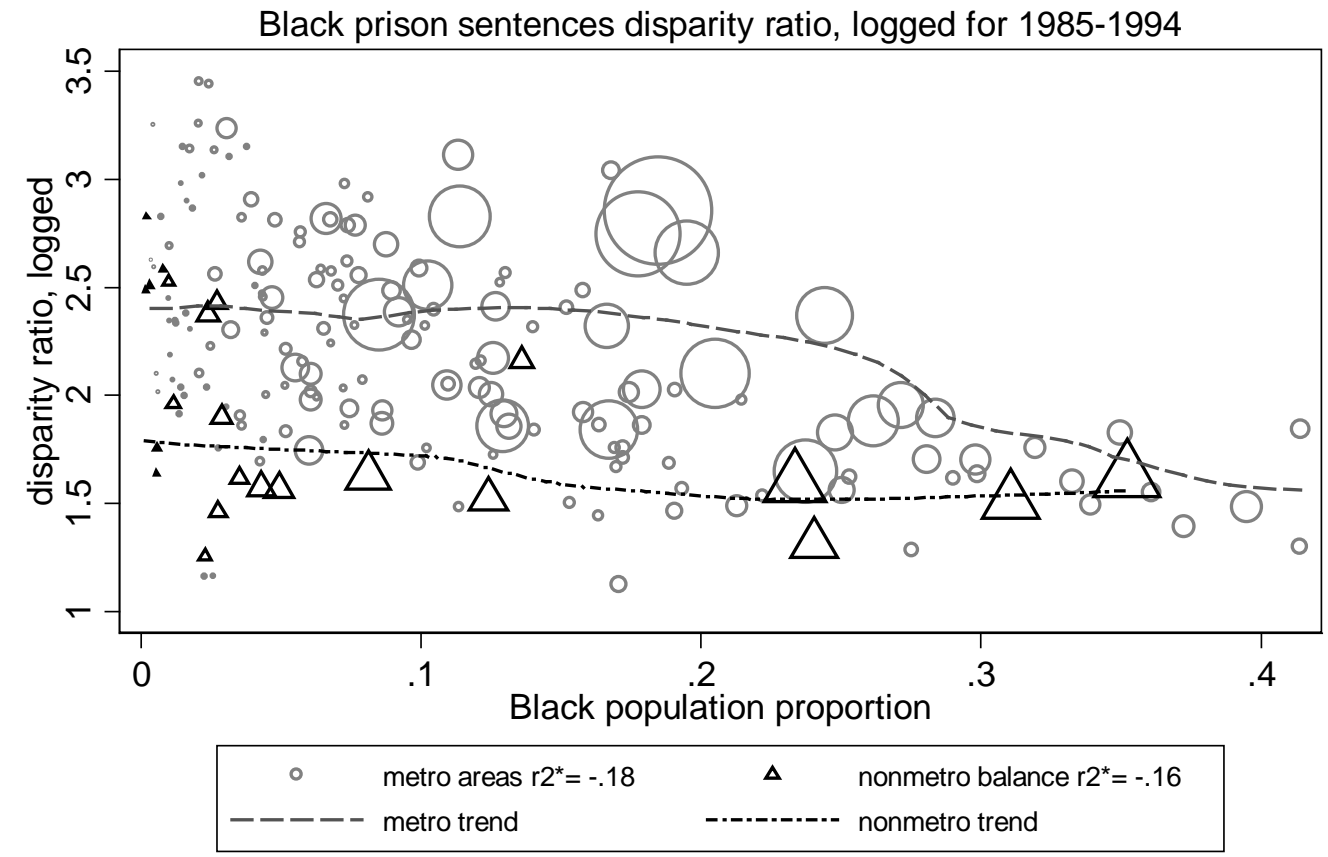

194 areas with complete prison data. Weighted by Black population $\mathrm{r} 2 *$ is signed $\mathrm{R} 2$

FIGURE 20. BLACK NEW SENTENCES DISPARITY, METRO AND NONMETRO AREAS 1985-1994 


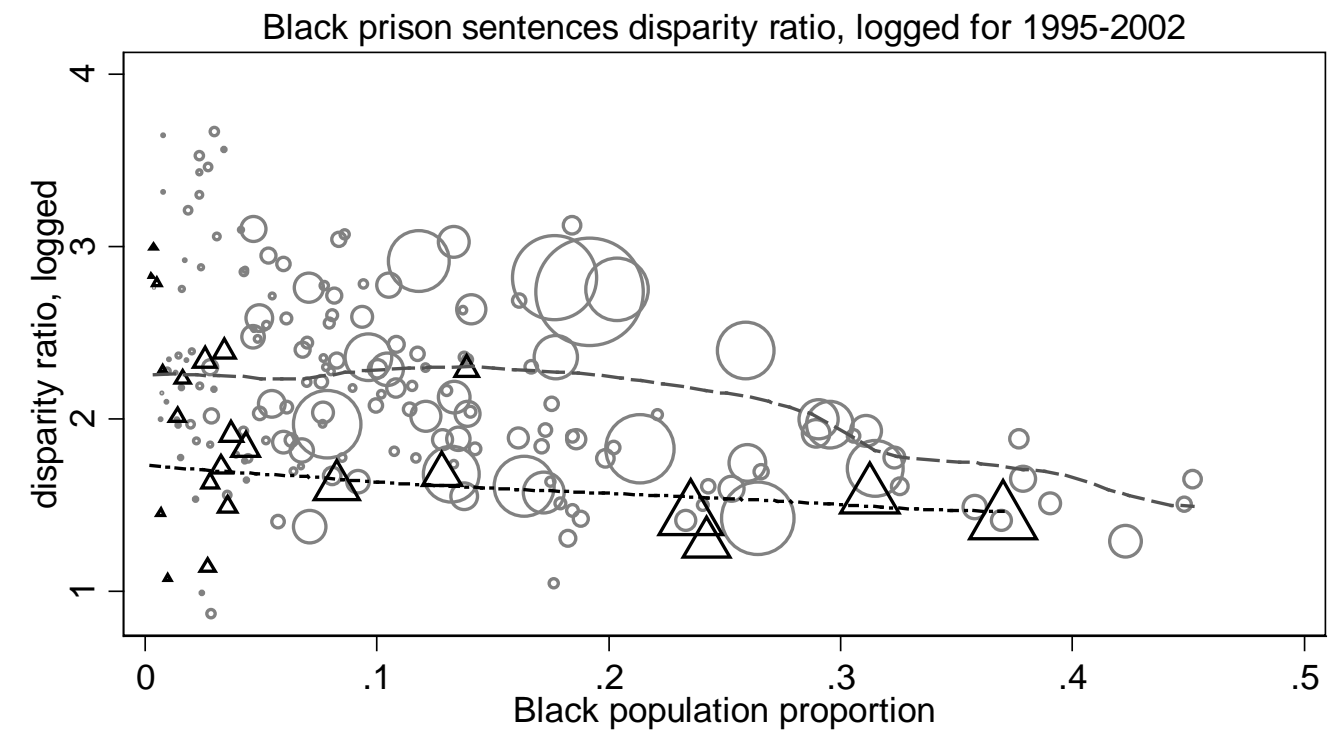

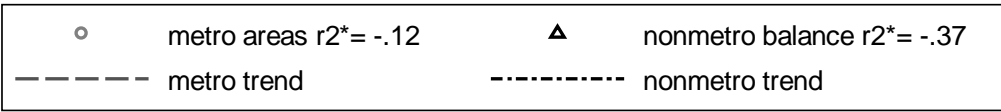

194 areas with complete prison data. Weighted by Black population $\mathrm{r} 2^{\star}$ is signed R2

FIGURE 21. BLACK NEW SENTENCES DISPARITY, METRO AND NONMETRO AREAS 1995-2002 
Hispanic Imprisonment by Hispanic Population Proportion

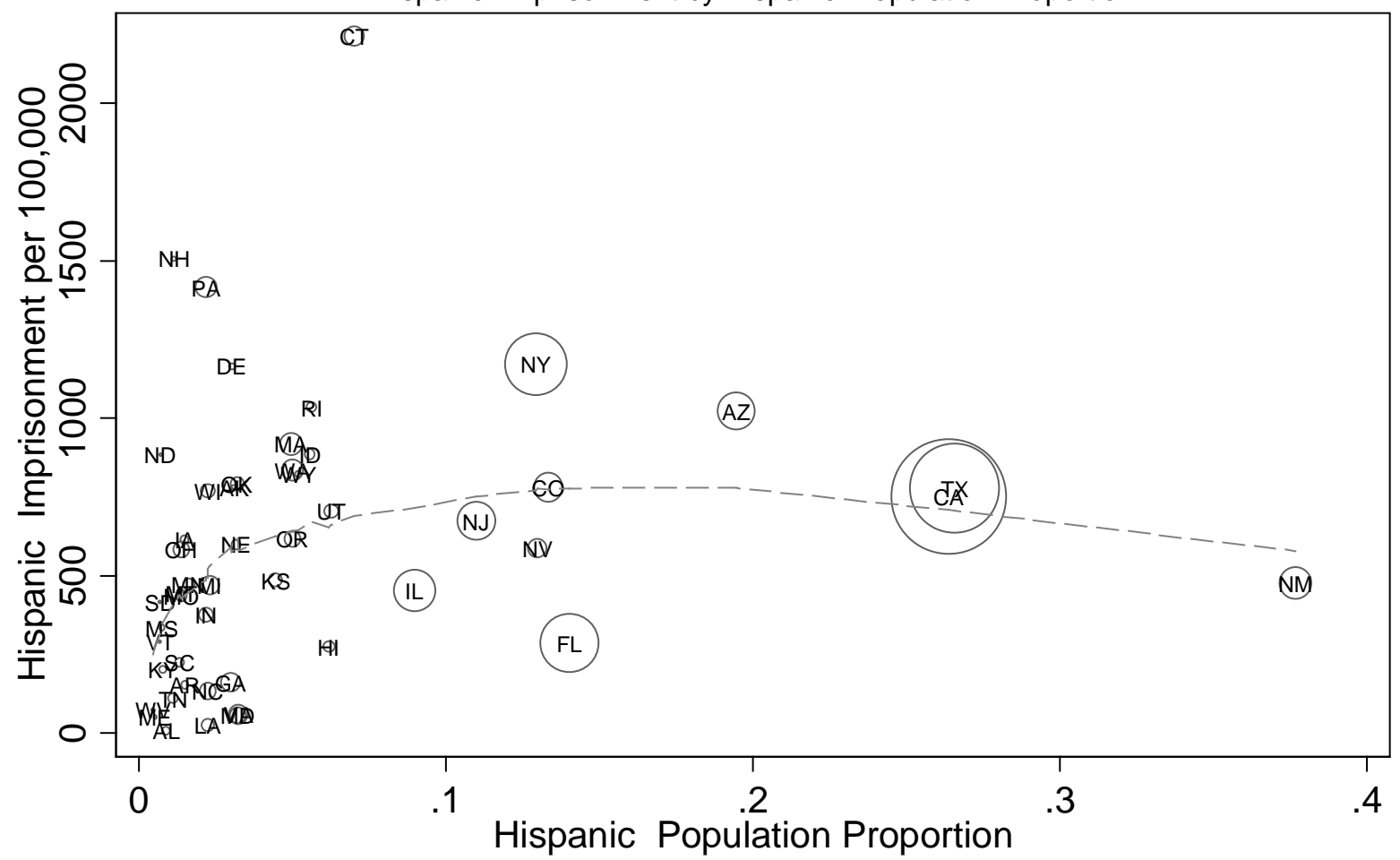

Correlation $=.2 ; \mathrm{r} 2=.04$. Weighted by Hispanic Population

1993-1998

FIGURE 22. HISPANIC IMPRISONMENT RATE BY HISPANIC POPULATION PROPORTION 1993-1998 
Hispanic Imprisonment Disparity by Hispanic Population Proportion

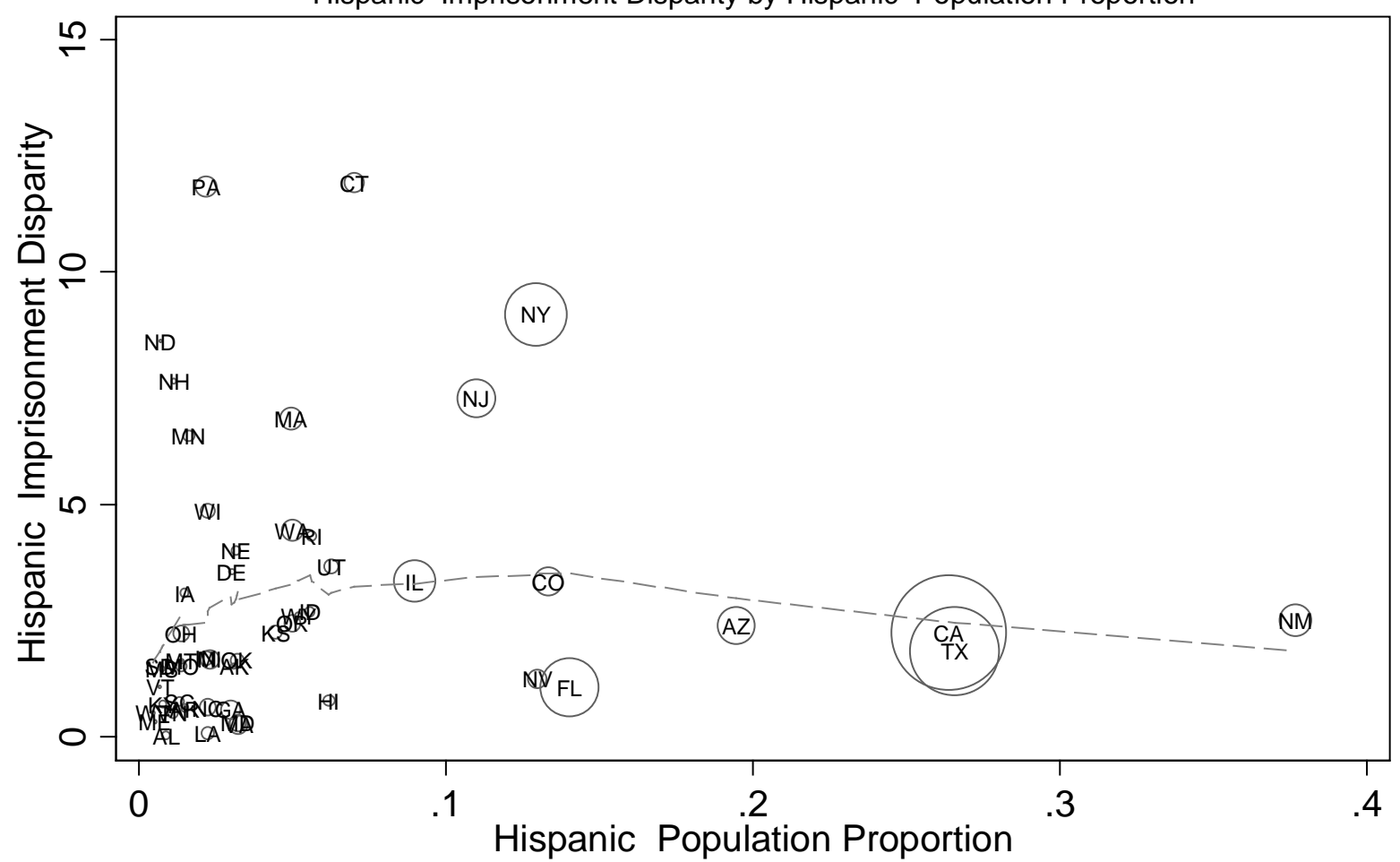

Correlation $=.05 ; \mathrm{r} 2=0$. Weighted by Hispanic Population

1993-1998

FIGURE 23. HISPANIC IMPRISONMENT DISPARITY BY HISPANIC POPULATION PROPORTION 1993-1998 
Hispanic Imprisonment Disparity by Hispanic Imprisonment

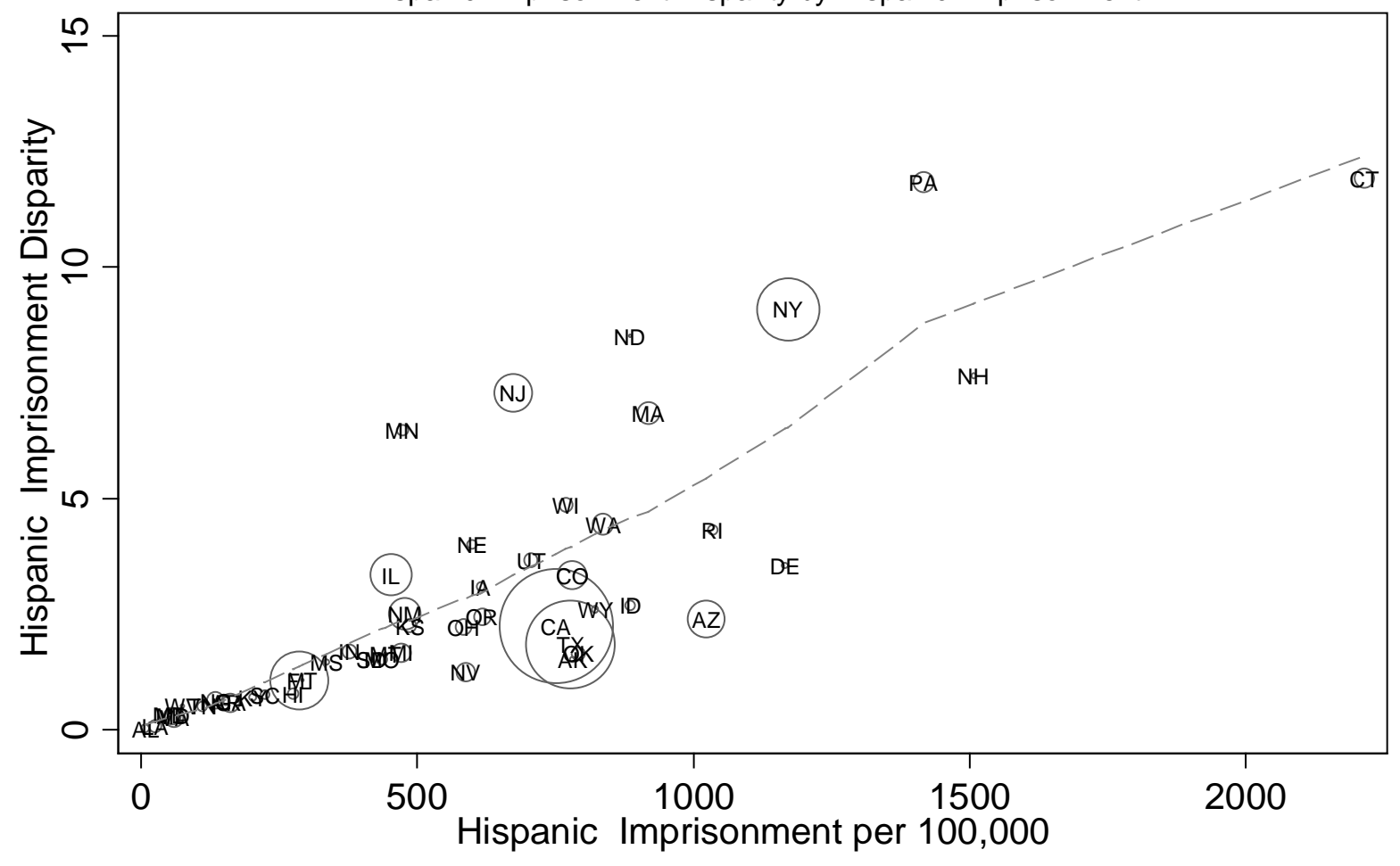

Correlation $=.82 ; \mathrm{r} 2=.67$. Weighted by Hispanic Population

1993-1998

FIGURE 24. HISPANIC IMPRISONMENT DISPARITY BY HISPANIC IMPRISONMENT RATE 1993-1998 


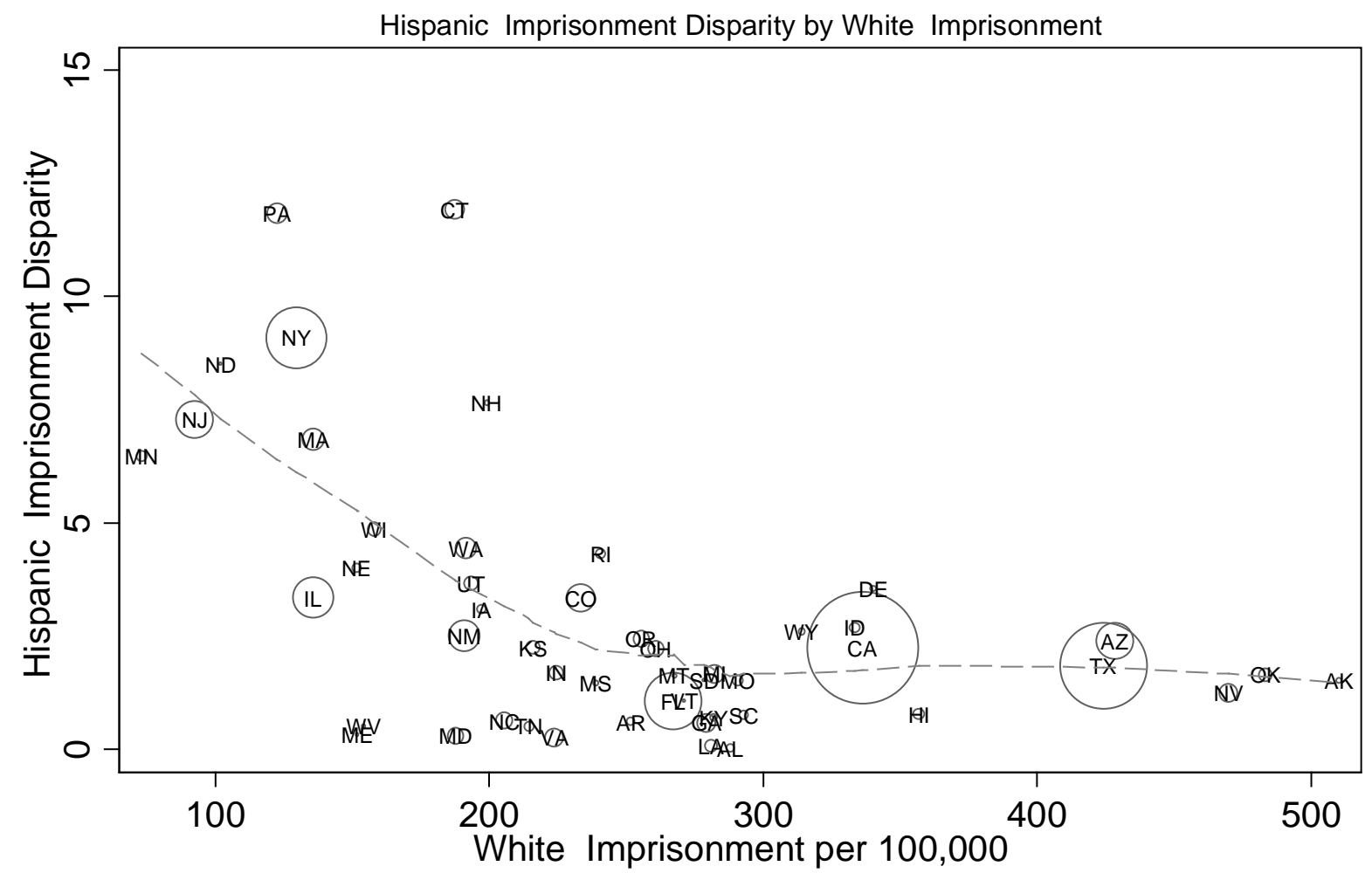

Correlation=-.48; $r 2=.23$. Weighted by Hispanic Population

1993-1998

FIGURE 25. HISPANIC IMPRISONMENT DISPARITY BY WHITE IMPRISONMENT RATE 1993-1998 


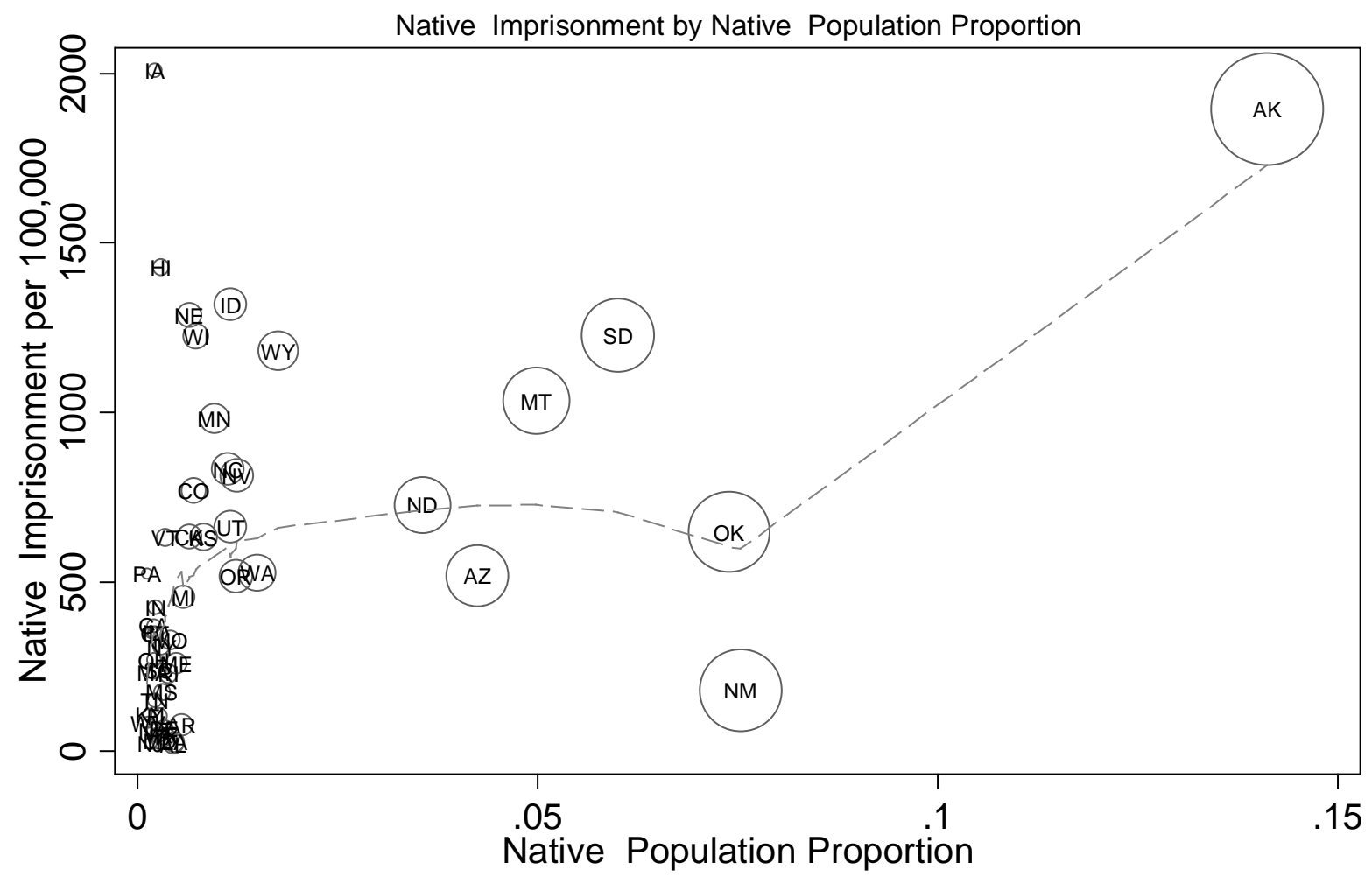

Correlation $=.42 ; r 2=.17$. Weighted by Native Population

1993-1998

FIGURE 26. NATIVE IMPRISONMENT RATE BY NATIVE POPULATION PROPORTION 1993-1998 


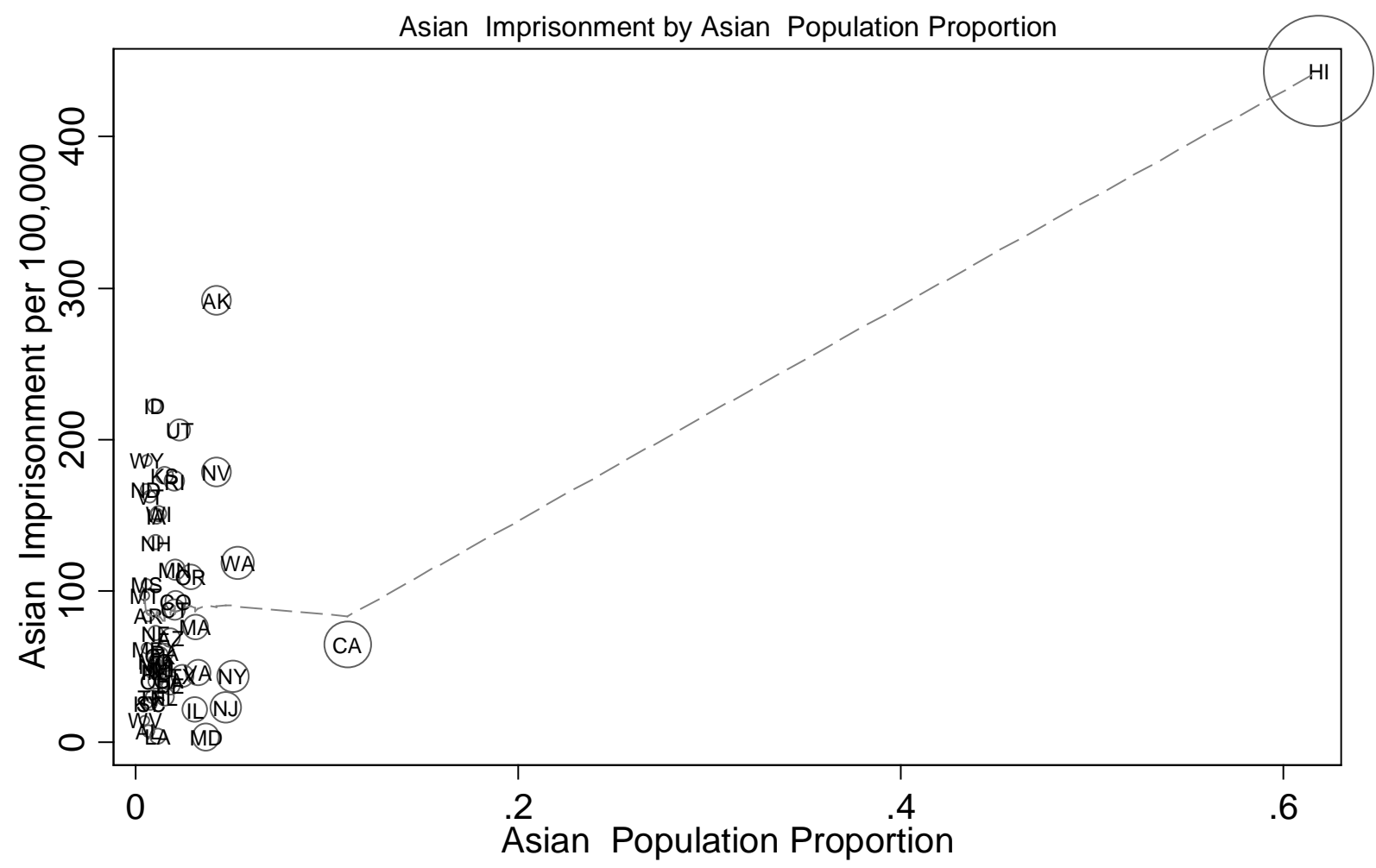

Correlation $=.58 ; \mathrm{r} 2=.33$. Weighted by Asian Population

1993-1998

FIGURE 27. ASIAN IMPRISONMENT RATE BY ASIAN POPULATION PROPORTION 1993-1998 


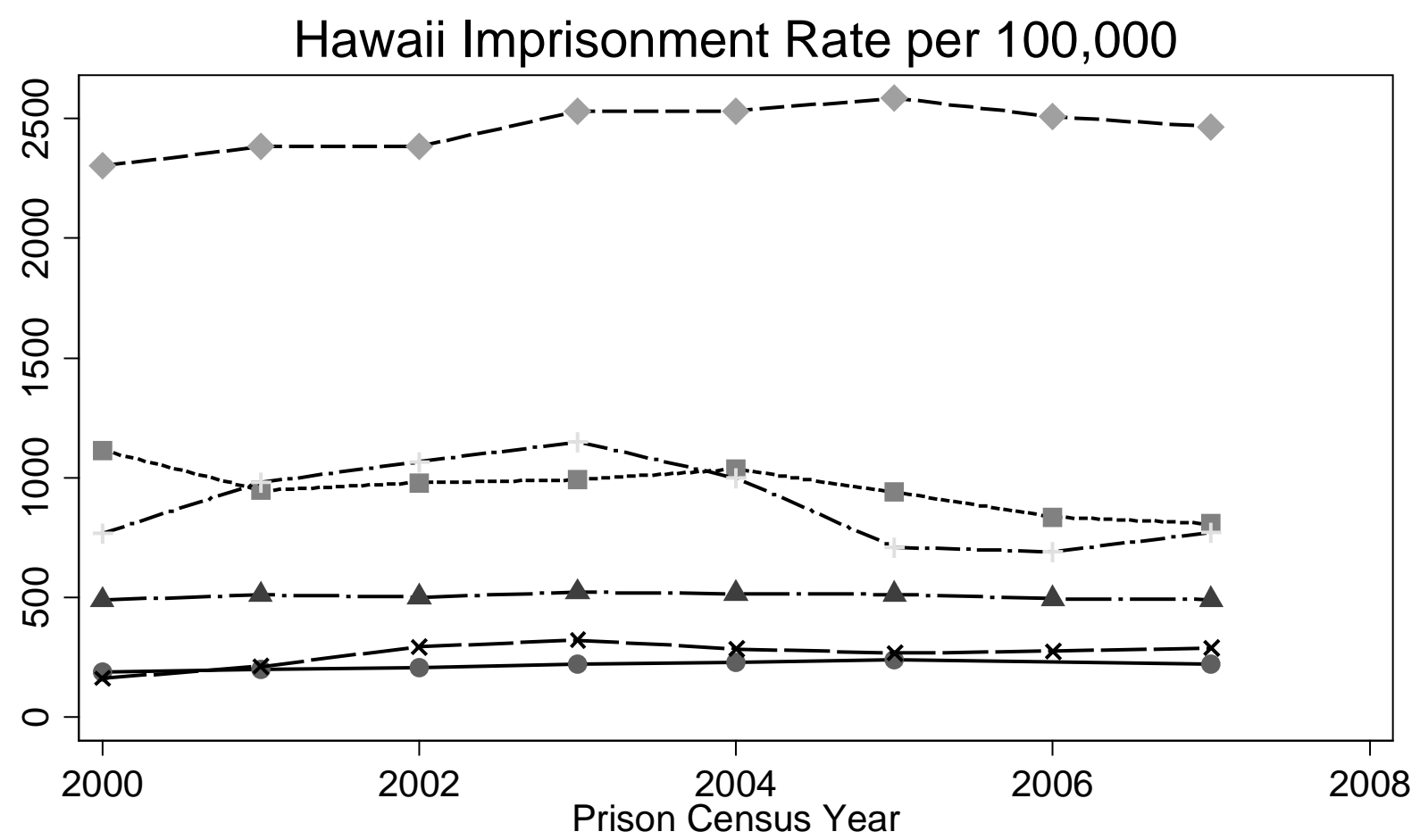

$\longrightarrow$ Asian not PI - - - Paclsland ---.---- Black ——. White - * Hispanic -.-.-. Native

FIGURE 28. HAWAII IMPRISONMENT RATES PER 100,000 2000-2007 


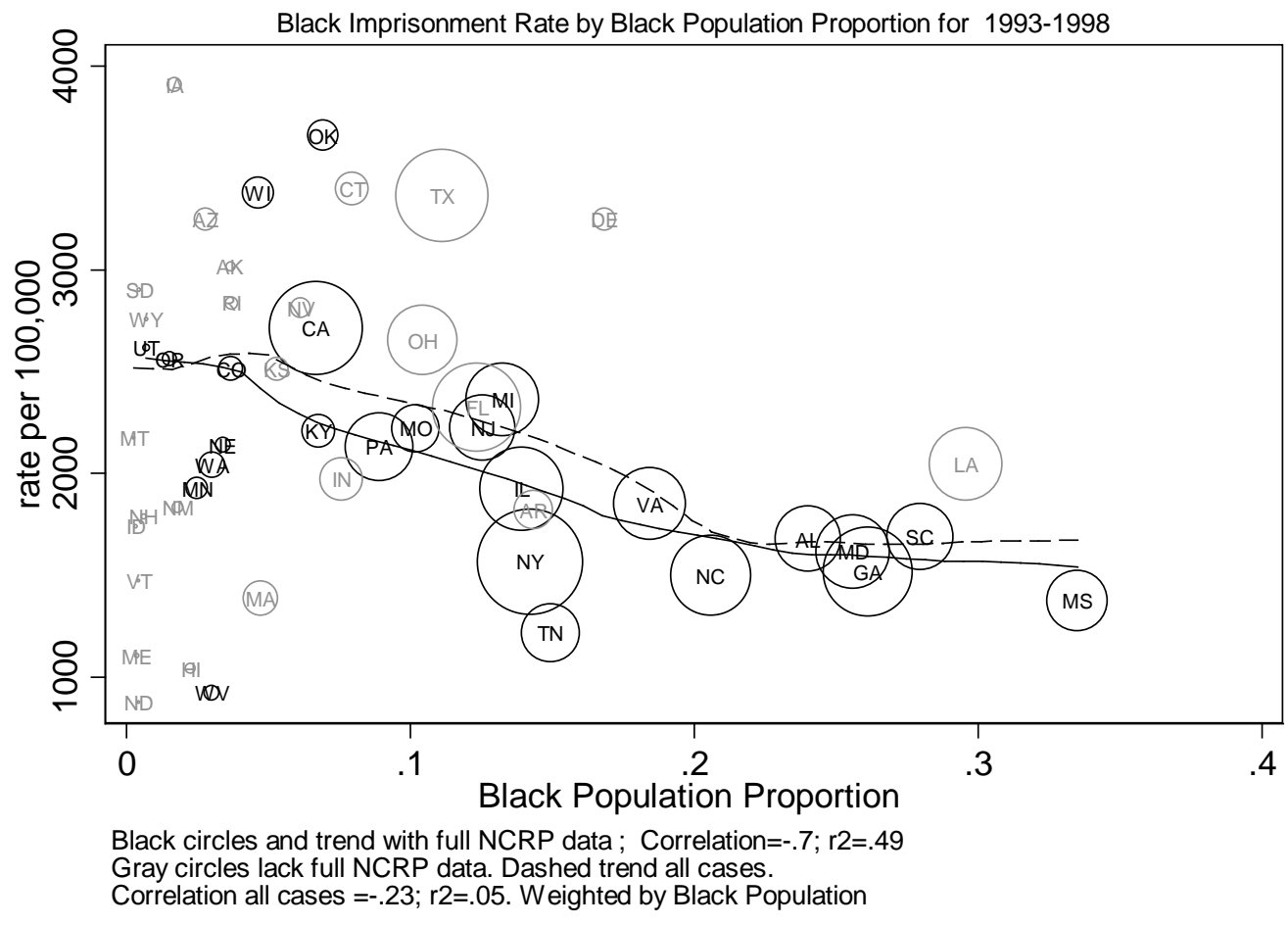

FIGURE 29. BLACK IMPRISONMENT RATE BY BLACK POPULATION PROPORTION FOR 1993-1998, NCRP VS NON_NCRP STATES 


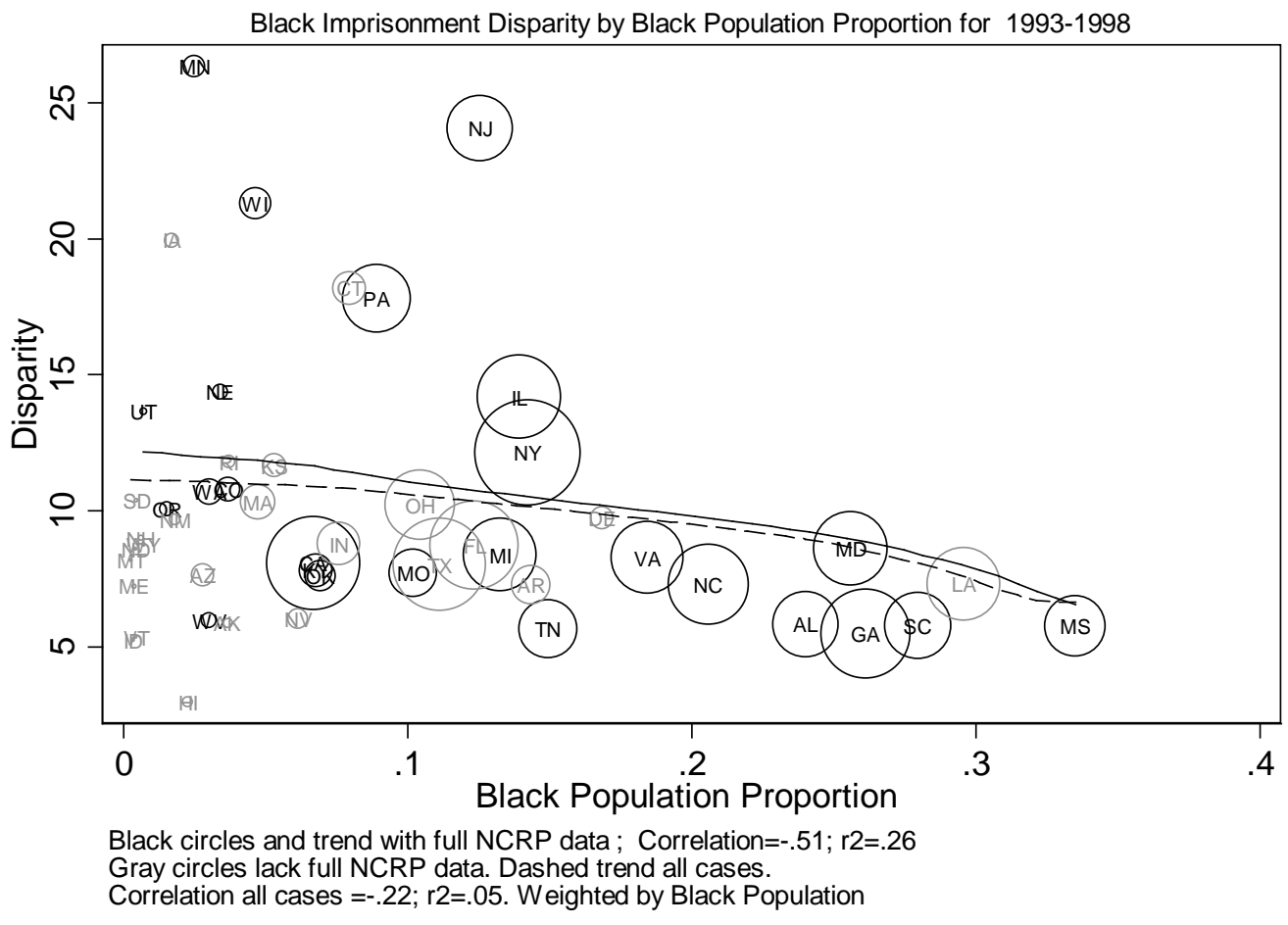

FIGURE 30. BLACK IMPRISONMENT DISPARITY BY BLACK POPULATION PROPORTION FOR 1993-1998, NCRP VS NON-NCRP STATES 


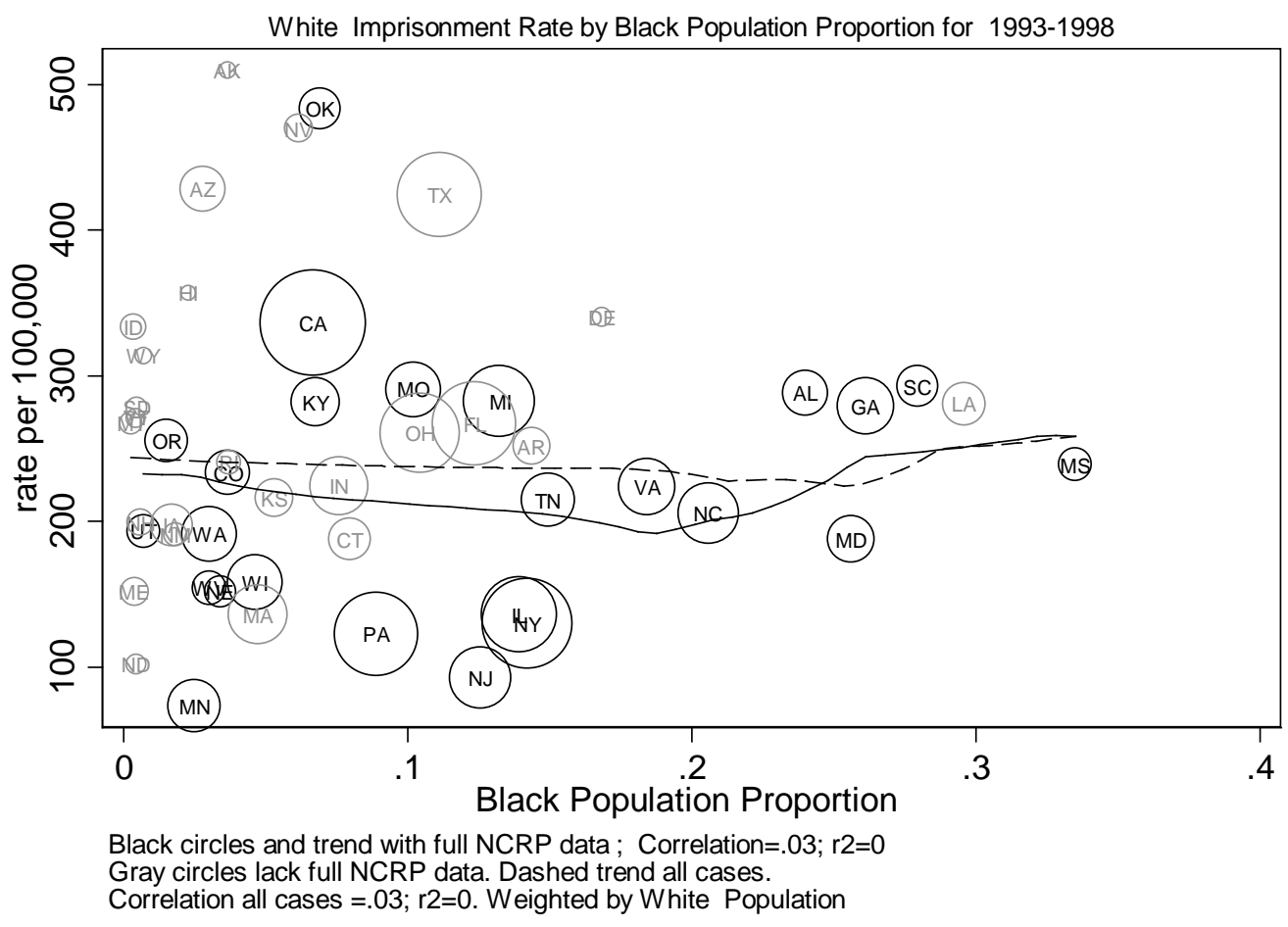

FIGURE 31. WHITE IMPRISONMENT RATE BY BLACK POPULATION PROPORTION FOR 1993-1998, NCRP VS NON-NCRP STATES 


\section{References}

1 See Oliver, Pamela E. 2008. "Regionalism and Percent Black: Trends 1926-1982." in available at http://ssc.wisc.edu/ oliver/RACIAL/Reports/Regionalism\%20and\%20Percent\%20Black\%20Historical\%20Trends\%20 1926-82.pdf.

${ }^{2}$ (citing an unpublished paper by me and a coauthor Oliver, Pamela E., and James E. Yocom. 2004. "Explaining State Black Imprisonment Rates 1983-1999." in American Sociological Association. San Francisco. and using our earlier compilation of data from the NCRP)

${ }^{3}$ This is true even in Bridges and Crutchfield's article which, as noted, develops an explanation that is consistent with Blalock's theorizing.

${ }^{4}$ The District of Columbia, which is majority Black, is excluded from this graph. It had a high Black imprisonment rate and an above-average racial disparity.

${ }^{5}$ The methodological note at the end of this paper compares the CPUS for the states with and without full NCRP data.

${ }^{6}$ As rural patterns have turned out to be important for Whites, the wisdom of hindsight says that a more detailed analysis of rural counties would be useful, but that is not possible within the scope of this project, as it would involve completely backing up to the individual-level records and completely re-creating the data set.

${ }^{7}$ California accounted for $30 \%$ of all Black revocation admissions. For Blacks, the next states were New York at $8 \%$ and Texas and Georgia at $7 \%$.

${ }^{8}$ These patterns also occur in MSA-level arrest data, not shown. The Black/White disparity in the ratio of prison sentences to arrests also is negatively correlated with the percent Black, although the relationship is weak. The graphs for arrests are not included in this manuscript.

${ }^{9}$ The percent minority pattern also replicates for Hispanics, although the Hispanic population is concentrated into many fewer areas, as figures 24 [htotohpoppyr3met.wmf] and 25 [htotdhpoppyr3met.wmf] indicate. The few MSAs that have a high percentage of Hispanics have low Hispanic prison admission rates, and again being below roughly $20 \%$ minority seems to be necessary but not sufficient for a high disparity. For Hispanics, there is a tight cluster of areas with very few Hispanics and a very low percentage of Hispanics that have low Hispanic prison admission rates, and the rural areas of states generally have low Hispanic imprisonment rates.

10 A keyword search in Criminal Justice Abstracts revealed only one article discussing this pattern, a mention in passing in an article about the treatment needs of incarcerated Hawaiian women that mentions that Pacific Islander are $10 \%$ of women but $40 \%$ of women prisoners [ Stein Lee, Yetta. 2001. "The psychosocial needs of Hawaiian women incarcerated for drug-related crimes." Journal of Social Work Practice in the Addictions 1(4):4769.] An internet search also located an article written in 2004 that noted that Hawaii had contracted with a private prison in Minnesota to house prisoners who were disproportionately Native Hawaiians. http://www.prisonersofthecensus.org/news/2004/05/10/minnesota/ UPDATE: More recent news stories have covered this phenomenon. 